EUROPEAN CENTRAL BANK

EUROSYSTEM

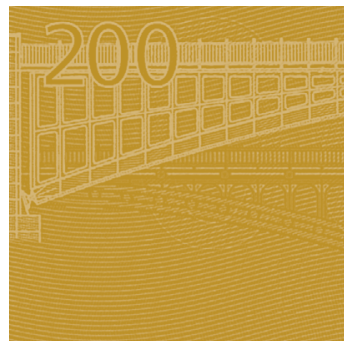

WORKING PAPER SERIES

NO I667 / APRIL 2014

\author{
ROLLOVER RISK, LIQUIDITY, AND \\ MACRO-PRUDENTIAL REGULATION
}

Toni Ahnert
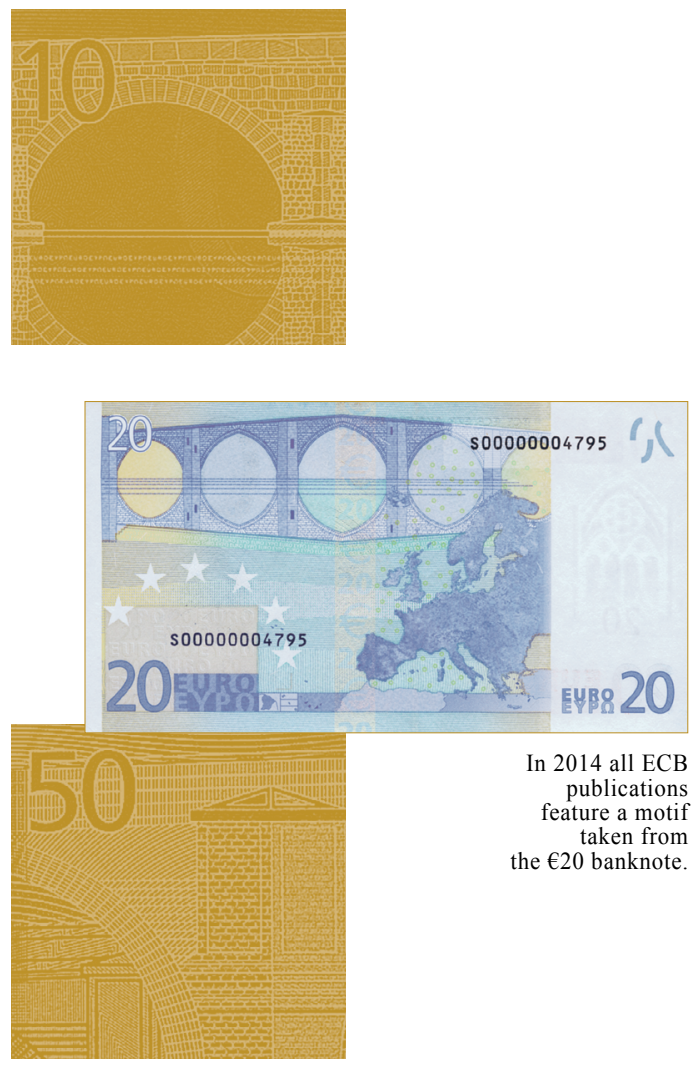

NOTE: This Working Paper should not be reported as representing the views of the European Central Bank (ECB). The views expressed are those of the authors and do not necessarily reflect those of the ECB. 


\section{Lamfalussy Fellowships}

This paper has been produced under the ECB Lamfalussy Fellowship programme. This programme was launched in 2003 in the context of the ECB-CFS Research Network on "Capital Markets and Financial Integration in Europe". It aims at stimulating high-quality research on the structure, integration and performance of the European financial system.

The Fellowship programme is named after Baron Alexandre Lamfalussy, the first President of the European Monetary Institute. Mr Lamfalussy is one of the leading central bankers of his time and one of the main supporters of a single capital market within the European Union.

Each year the programme sponsors five young scholars conducting a research project in the priority areas of the Network. The Lamfalussy Fellows and their projects are chosen by a selection committee composed of Eurosystem experts and academic scholars. Further information about the Network can be found at http://www.eufinancial-system.org and about the Fellowship programme under the menu point "fellowships".

\section{Acknowledgements}

This paper has been prepared by the author under the Lamfalussy Fellowship Program sponsored by the ECB. Any views expressed are only those of the author and do not necessarily represent the views of the ECB or the Eurosystem. I wish to thank Christoph Bertsch, Margaret Bray, Co-Pierre Georg, Stefan Gissler, Philipp Hartmann, Peter Hoffmann, Benjamin Nelson, Dimitri Vayanos, and seminar participants at Copenhagen IRMC 2013, LSE, Nottingham CFCM 2013, and UPF for useful feedback. The views expressed in this paper are those of the author and no responsibility for them should be attributed to the Bank of Canada.

\section{Toni Ahnert}

Bank of Canada; e-mail: tahnert@bankofcanada.ca

(C) European Central Bank, 2014

\section{Address \\ Postal address \\ Telephone \\ Internet \\ Fax}

All rights reserved.

\section{ISSN \\ EU Catalogue No}

Kaiserstrasse 29, 60311 Frankfurt am Main, Germany

Postfach 1603 19, 60066 Frankfurt am Main, Germany +496913440

http://www.ecb.europa.eu

+496913446000

$$
\begin{aligned}
& \text { 1725-2806 (online) } \\
& \text { QB-AR-14-041-EN-N (online) }
\end{aligned}
$$

Any reproduction, publication and reprint in the form of a different publication, whether printed or produced electronically, in whole or in part, is permitted only with the explicit written authorisation of the ECB or the authors.

This paper can be downloaded without charge from http://www.ecb.europa.eu or from the Social Science Research Network electronic library at http://ssrn.com/abstract_id=2418234.

Information on all of the papers published in the ECB Working Paper Series can be found on the ECB's website, http://www.ecb.europa.eu/pub/scientific/wps/date/html/index.en.html 


\begin{abstract}
I study rollover risk in the wholesale funding market when intermediaries can hold liquidity ex-ante and are subject to fire sales ex-post. I demonstrate that precautionary liquidity restores multiple equilibria in a global rollover game. An intermediate liquidity level supports both the usual run equilibrium and an efficient equilibrium. I provide a uniqueness refinement to characterize the privately optimal liquidity choice. Because of fire sales, liquidity holdings are strategic substitutes. Intermediaries free-ride on the liquidity of other intermediaries, causing excessive liquidation. A macro-prudential authority internalizes the systemic nature of liquidity and restores constrained efficiency by imposing a macro-prudential liquidity buffer.
\end{abstract}

JEL Classifications: G01, G11, G28.

Keywords: global games, multiplicity, portfolio choice, wholesale funding. 


\section{Non-technical summary}

The stability of the financial system is a key concern to central bankers. A particular aspect that has received much attention recently is the wholesale funding of banks. Before the financial crisis, banks funded themselves increasingly with short-term debt. However, such funding dried up as economic news deteriorated. This dark side of wholesale funding in part inspired the Basel III regulation. Specifically, a Liquidity Coverage Ratio (LCR) and a Net Stable Funding Ratio (NSFR) require banks to maintain a minimum level of liquidity.

In this paper I study rollover risk in wholesale funding markets. Investors may roll over funding to their intermediaries after receiving some noisy information about their solvency. My setup has two noteworthy features. First, financial intermediaries are allowed to hold precautionary liquidity in order to prepare for the possible future dry-up of funding. That is, intermediaries choose how much liquidity to hold initially, while the remainder is invested in illiquid projects with high expected returns. Second, a fire sale occurs when intermediaries liquidate their projects jointly.

This paper derives two main results. The first result is technical and states that the methods previously used to ensure a unique equilibrium require a refinement. That is, I show how uniqueness in the global rollover game prevails when intermediaries hold precautionary liquidity. Uniqueness is a crucial feature because it puts the subsequent welfare analysis on a strong theoretical footing.

The second result shows the inefficiency of private liquidity holdings. Since intermediaries freeride on the liquidity holdings of other intermediaries, there is excessive liquidation. By contrast, a macro-prudential authority internalizes the systemic nature of liquidity, whereby the liquidity holding of one intermediary mitigates the risk of fire sales for other intermediaries. Efficiency is restored by imposing a macro-prudential liquidity buffer.

Finally, I link this welfare result to the regulatory debate of Basel III. I argue why this setup provides a theoretical foundation for the Liquidity Coverage Ratio. While it also provides some support for the Net Stable Funding Ratio, I describe how the present setup could be extended to address the trade-offs associated with the NSFR more directly. 


\section{Introduction}

Wholesale funding markets have received a great deal of attention since the financial crisis of 20072009. Financial institutions funded themselves with very short-term debt provided by uninsured investors. This funding dried up after adverse economic news, such as disappointing data on the US housing market. Huang and Ratnovski (2011) point to the dark side of wholesale funding when investors are relatively uninformed. During the financial crisis, money market mutual funds also experienced large outflows from institutional investors (Schmidt et al. (2013)) and even secured short-term borrowing was a highly unstable source of funds (Martin et al. (2013)). These events in part inspired the recent proposals for the regulation of financial intermediaries, which include balance sheet rules like maintaining a Liquidity Coverage Ratio (LCR) and a Net Stable Funding Ratio (NSFR) (The Basel Committed (2010a, b) ).

To address these issues, I study rollover risk in the wholesale funding market, where uninsured investors may withdraw funding from intermediaries at an interim date 1 Intermediaries choose their portfolio at the initial date, either holding safe and low-return assets (liquidity) or making long-term investment. While promising a higher expected return, investment is costly to liquidate at the interim date because of a lower and diminishing marginal product in alternative use (Shleifer and Vishny (1992), Kivotaki and Moore (1997)). This cost of liquidation is exacerbated by fire sales that occur when many intermediaries liquidate jointly (Allen and Gale (1994), Gromb and Vayanos (2002)). The stochastic return on investment is determined by aggregate economic conditions like business cycle movements, which determine default rates 2

Each investor receives a noisy private signal about the return on investment at the interim date, based on the global games approach in Morris and Shin (2003). Using the private information, each investor decides whether to roll over funding to the intermediary. As a result, a low (high) realization of the investment return implies that many (few) investors receive unfavorable private information. Hence, a small (large) proportion of investors rolls over their funding to the intermediary, which results in a large (small) amount of investment that the intermediary liqui-

\footnotetext{
${ }^{1}$ I use "refusing to roll over" and "withdrawing" interchangeably.

${ }^{2}$ In case of financial investment, changing aggregate conditions can represent a shock to an asset class in which all intermediaries are invested, such as the effect of a drop in US house prices on asset-backed securities.
} 
dates. However, holding precautionary liquidity allows the intermediary to drive a wedge between the withdrawal and liquidation volumes.

The first result is that the presence of liquidity generates multiple equilibria in the global rollover game (Proposition 1). The usual condition of fairly precise private information (e.g. Morris and Shin (2000)) is not sufficient for uniqueness. On the one hand, an efficient equilibrium exists if an intermediary holds an intermediate or high amount of liquidity (Lemma 1). On the other hand, the typical run equilibrium also exists if an intermediary holds a low or intermediate amount of liquidity (Lemma 2). Hence, an intermediate choice of liquidity supports multiple equilibria in the rollover game between investors, even if the private information received is fairly precise. This result, which hinges on the presence of precautionary liquidity holdings, contributes to a recent literature on multiplicity in global coordination games. For example, Angeletos et al. (2006) examine how the endogenous public information from a policy intervention generates multiple equilibria and Hellwig and Veldkamp (2009) analyse when the acquisition of information prior to coordination leads to multiple equilibria 3

To obtain intuition for the multiplicity result, consider the strategic incentives of investors to roll over funding (see section 2 and Remark 1). Despite the risk neutrality of all agents, the incomplete-information game with liquidity holdings yields intriguing strategic interactions, which differ across the cases with and without liquidation. First, intermediate liquidity holdings can support the efficient equilibrium in which no liquidation is forecast by the threshold investor, resulting in a low equilibrium threshold. Exactly at this point, the strategic incentives to roll over funding change from complementarity to substitutability. Second, intermediate liquidity holdings can also support the run equilibrium in which positive liquidation is forecast. Then, there is global strategic complementarity in rollover decisions that leads to coordination failure between investors, resulting in a high equilibrium threshold (e.g., Morris and Shin (2000)) 4

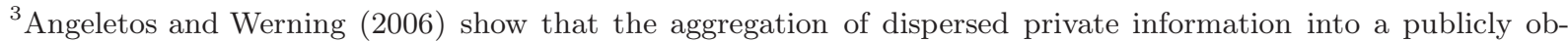
served market price, similar to Grossman and Stiglitz (1980), re-establishes multiplicity in a global game. See also Hellwig et al. (2006) for a market-based model of currency attacks with multiple equilibria.

${ }^{4}$ Rochet and Vives (2004) analyse the impact of balance sheet variables, including liquidity, on the run threshold in the context of delegated management, which gives rise to a unique Bayesian equilibrium. By contrast, the rollover game I study may yield multiple equilibria. However, once the uniqueness refinement is applied, I replicate the effect of liquidity on the run threshold stated in their second proposition. Another difference is the analysis of two intermediaries that allows me to study the private and social incentives to hold liquidity from a systemic perspective. 
To analyse the private incentives to hold liquidity, I provide a uniqueness refinement (Corollary 2). Consider first the benchmark of a single intermediary. The choice of liquidity balances the opportunity cost of a higher expected return on investment with the saved cost of liquidation, which reduces the equilibrium threshold in the run equilibrium. The intermediary optimally holds scarce liquidity and implements the run equilibrium in the rollover game if the expected return on investment takes an intermediate value (Proposition 2). Additionally, the intermediary holds no liquidity at all if the expected return takes a sufficiently large value, where this lower bound on the expected return intuitively increases in the liquidation cost.

The portfolio choice of the single intermediary is constrained efficient (Corollary 3). A planner who takes the optimal rollover behavior of investors as given holds the same level of liquidity. As such, there is no role for a micro-prudential regulation of liquidity. Despite the constrained efficiency, the incomplete information about the return on investment may prevent the decentralized economy from achieving first-best 5

Consider now the main case of multiple intermediaries. The run equilibrium is again implemented if the expected return is sufficiently high, so the private choices of liquidity are strategic substitutes (Proposition 3). Therefore, each intermediary free-rides on the liquidity holdings of other intermediaries. If one intermediary holds more liquidity, the liquidation cost of another intermediary is reduced as the effect of fire sales is less pronounced. Since holding liquidity is costly due to the foregone return on investment, the other intermediary optimally reduces its liquidity holding. As a result, excessive liquidation occurs that renders the private choice of liquidity as constrained inefficient from an ex-ante perspective.

This yields a role for a macro-prudential regulation of liquidity (Proposition 44). A constrained planner internalizes the systemic nature of liquidity and is therefore interpreted as a macroprudential authority. Specifically, it takes into account that more liquidity held by one intermediary reduces the liquidation cost of other intermediaries in case of ex-post fire sales. Therefore, the social choice of liquidity exceeds the private choice, so imposing a macro-prudential liquidity buffer

\footnotetext{
${ }^{5}$ That is, if the expected return on investment is low, the intermediary holds abundant liquidity. This implements the efficient equilibrium in the rollover game and attains first-best. In contrast, if the expected return is high, the intermediary holds scarce liquidity and implements the run equilibrium. First-best is not attained since coordination failure between investors leads to inefficient liquidation ex-post.
} 
restores constrained efficiency. As a consequence, inefficient liquidation occurs for the smallest possible range consistent with incomplete information.

The most related papers are the global rollover games of Morris and Shin (2000) and Eisenbach (2013). Building on the seminal works of Carlsson and van Damme (1993) and Diamond and Dybvig (1983), Morris and Shin (2000) use global games techniques to solve for the unique equilibrium in a bank run game 6 By contrast, I analyse the ex-ante portfolio choice of intermediaries and show how precautionary liquidity can restore multiple equilibria under the sufficient condition proposed by Morris and Shin (2000).7 Furthermore, I extend the analysis to multiple intermediaries and fire sales to explore macro-prudential regulation of liquidity. Eisenbach (2013) also analyses an ex-post coordination game in which investors rollover short-term debt. He studies the ex-ante optimal maturity choice of funding to discipline a bank manager tempted by moral hazard and derives a two-sided inefficiency. In contrast, I study the optimal portfolio choice of intermediaries on the asset side.

Other consequences of fire sales have already been analysed. Wagner (2011) studies the diversification-diversity trade-off in ex-ante portfolio choices. Since joint liquidation is costly expost, investors have an incentive to hold diverse portfolios ex-ante 8 In contrast, I examine the consequences of fire sales for the ex-ante liquidity holdings of intermediaries subject to rollover risk. Uhlig (2010) studies endogenous liquidation costs in a model of a two-tiered banking sector, where a system-wide externality also generates strategic complementarities in withdrawal decisions between investors. Instead of a positive analysis of the previous financial crisis and a discussion of ex-post policy interventions, I take an ex-ante perspective by focusing on macro-prudential regulation of liquidity. Studying ex-ante regulation has the advantage of precluding the issue of moral hazard arising from an ex-post policy intervention, as stressed by Farhi and Tirole (2012).

\footnotetext{
${ }^{6}$ Multiple Nash equilibria in Diamond and Dvbvig (1983) occur because of self-fulfilling beliefs. In a setup closer to this model, Goldstein and Pauzner (2005) also obtain a unique equilibrium by extending the global games techniques to the case of one-sided strategic complementarities. See section 5 for a comparison of the strategic incentives of investors to the setup studied in this paper.

'Vives (2013) and Morris and Shin (2010) also analyse the role of liquidity in rollover coordination games. However, they do not study the ex-ante portfolio choice of intermediaries and abstract from cases that induce the efficient equilibrium in the rollover game.

Wagner (2009) analyses the effect of ex-post fire sales on the ex-ante diversification choice of banks. He finds ambiguous welfare implications of optimal diversification choices, since banks may be 'too correlated' (as in the standard case) or 'too diversified' under laissez faire.
} 


\section{Model}

I present a simple model of financial intermediation that extends the single-intermediary model of Morris and Shin (2000) in two ways. First, there are many intermediaries whose ex-post liquidation decisions impose fire-sale externalities on each other. Second, intermediaries are allowed to hold precautionary liquidity. This setup is suitable to revisit the issue of equilibrium uniqueness in a global rollover game and to analyse the ex-ante liquidity choices and their welfare properties.

Agents and preferences The economy extends over three dates, $t \in\{0,1,2\}$, and there is a single good for consumption and investment. A finite number of intermediaries $N \in\{1,2\}$ raise funds from a continuum of risk-neutral uninsured investors $i \in[0, N] 99$ Investors consume at the final date and receive a payoff $\pi_{i}=c_{2}$. They are akin to wholesale short-term debt holders who played a pivotal role in the recent financial crisis.

Investment technology and funding Intermediaries simultaneously choose their portfolios at the initial date. Intermediaries can hold a liquid asset $y_{n}$, such as central bank reserves and government bonds, which yield a unit safe return at the subsequent date. They can also invest by originating loans to the real economy at the initial date, which constitutes a constant returns-toscale technology, that yield a risky payoff $r$ at the final date. The portfolio choice of intermediaries is publicly observed at the interim date.

Investors are endowed with one unit of the good at the initial date. Apart from claims on the intermediary, investors can hold liquidity but direct investment is infeasible because of inferior skills in monitoring or loan collection. The intermediary is funded purely with debt 10 Because of free entry, an intermediary maximizes the expected utility of its investors (see also Gale (2010)). Combined with the intermediary's access to investment, the participation constraint of investors is satisfied and each intermediary attracts one unit of funding at the initial date 11

\footnotetext{
${ }^{9}$ This specification ensures a constant average amount of funding per intermediary.

${ }^{10}$ Absent an agency conflict between the intermediary and its debt holders, there is no role for micro-prudential regulation of intermediaries (Corollary 3). Thus, equity is not required as an incentive device.

${ }^{11}$ Instead of providing liquidity insurance for risk-averse investors (Diamond and Dybvig (1983)), financial intermediation occurs in this paper because of an intermediary's superior monitoring or loan collection skills.
} 
Information The following information structure is common knowledge. Investors share a common prior about the profitability of risky investment:

$$
r \sim \mathcal{N}\left(\bar{r}, \alpha^{-1}\right)
$$

where investment produces an expected return superior to liquidity, $\bar{r}>1$, and $\alpha \in(0, \infty)$ measures the precision (inverse variance) of public information 12 Following the seminal contribution of Carlsson and van Damme (1993), the return on the risky investment is realized at the interim date but not publicly observed. Instead, each investor receives a private signal at the interim date:

$$
x_{i}=r+\epsilon_{i}, \epsilon_{i} \sim \mathcal{N}\left(0, \gamma^{-1}\right)
$$

where the idiosyncratic noise $\epsilon_{i}$ is identically and independently distributed as well as independent of the investment return, and $\gamma \in(0, \infty)$ measures the precision of private information.

Liquidity-return trade-off Loans are costly to liquidate at the interim date. As in Morris and Shin (2000), the liquidation of an amount $l_{n} \in[0,1]$ by intermediary $n$ reduces the final-date return by $\chi_{n}\left(l_{n}, l_{-n}\right)$, where $l_{-n}$ is the amount of liquidation by the other intermediary. This specification allows for many intermediaries compared to the case of a single intermediary in Morris and Shin (2000). Costs occur only in case of liquidation, so $\chi_{n}(0, a)=0 \forall a \geq 0$. To ensure that liquidity is not dominated, I assume $\bar{r}<1+\chi(1,1)<\infty$ throughout.

The liquidation cost is determined endogenously from a downward-sloping demand for liquidated investment as in Eisenbach (2013). For example, assets are relocated to another, less productive sector (Shleifer and Vishny (1992), Kiyotaki and Moore (1997)). 13 Since the marginal product of liquidated assets in alternative use is strictly positive, continuous, and diminishing, the cost function is symmetric, weakly convex, and increases in an intermediary's liquidation volume

\footnotetext{
${ }^{12}$ This prior may be induced by a public signal: $\bar{r}=r+\eta$, where the noise $\eta \sim \mathcal{N}\left(0, \alpha^{-1}\right)$ is independent of the return. Furthermore, the aggregate noise is independent of each of the idiosyncratic noise terms $\epsilon_{j}$.

${ }^{13}$ In Shleifer and Vishny (1992), liquidation values are depressed after an industry-specific shock since distress sales take place to unlevered industry outsiders who value industry-specific assets less.
} 
conditional on a positive amount of liquidation, $l_{n}>0$ :

$$
\frac{\partial \chi_{n}}{\partial l_{n}}>0 \text { if } l_{n}>0
$$

Fire sales occur when intermediaries jointly liquidate investment:

$$
\frac{\partial \chi_{n}}{\partial l_{-n}}>0 \text { if } l_{n}>0
$$

Limited participation in asset markets can lead to cash-in-the-market pricing and therefore underpricing of assets (Allen and Gale (1994)). In the interpretation of financial investment, financial arbitrageurs cannot pick up assets in fire sales since they are constrained by losses and outflows themselves (Gromb and Vayanos (2002)). Where loans are secured on real estate, for example, foreclosures generate negative spillovers for the owners of nearby property. Campbell et al. (2011) quantify this effect for housing in Massachusetts, finding that forced sales following bank foreclosures take place at discounts of up to 27 per cent.

A simple specification of the liquidation cost function that satisfies all constraints is:

$$
\chi_{n}\left(l_{n}, l_{-n}\right)=\chi \cdot\left[l_{n}+l_{-n}\right] 1\left\{l_{n}>0\right\}
$$

for some constant $\chi>0$. I use the general specification in the first part of the paper. When analysing welfare, I restrict attention to the simple specification, which produces succinct results.

Upon receiving the private information $x_{i}$, investors may withdraw their funds at par at the interim date 14 A proportion of investors $w_{n} \in[0,1]$ withdraws and is served with liquidity. In case of high withdrawals, $w_{n}>y_{n}$, intermediaries also liquidate some investment $l_{n} \equiv w_{n}-y_{n} \in\left[0,1-y_{n}\right]$. In this case, more liquidity reduces the liquidation cost by driving a wedge between withdrawals and liquidation. Hence, an intermediary may hold precautionary liquidity ex-ante to avoid costly liquidation in states with high withdrawals ex-post.

\footnotetext{
${ }^{14}$ Similar to Dasgupta (2004), Goldstein (2005), and Shapiro and Skeie (2013), this ensures the viability of intermediaries at the interim date since the promised payment does not exceed the liquidation value.
} 


\subsection{Payoffs and strategic incentives to roll over}

What are the strategic incentives to roll over funding to an intermediary? To address this, consider for now the benchmark case of common knowledge about the investment return. The payoffs, and thus the strategic incentives to rolling over, depend critically on the liquidation volumes of each intermediary. I consider the cases of no liquidation and some liquidation in turn.

First, if many investors withdraw from intermediary $n$, all liquidity is exhausted and some liquidation occurs. Then the payoff to an investor who rolls over to this intermediary simplifies to:

$$
c_{2 n}=r-\chi_{n}\left(l_{n}, l_{-n}\right)
$$

Second, if withdrawals are small relative to the intermediary's liquidity holdings, then no liquidation occurs and the payoff to an investor who rolls over is:

$$
c_{2 n}=\frac{y_{n}-w_{n}+\left(1-y_{n}\right) r}{1-w_{n}}
$$

where investors that roll over share the proceeds from some excess liquidity and investment.

How is an investor's incentive to roll over affected by more withdrawals from the same intermediary? There is strategic complementarity in rolling over decisions if liquidation occurs, $l_{n}>0$. The more investors of intermediary $n$ roll over, the smaller the liquidation cost, and the higher the relative payoff from rolling over.

However, if no liquidation occurs, the strategic incentives depend on the realized investment return (if the intermediary makes some investment, $y_{n}<1$ ). If the investment return is low, $r<1$, then there is again strategic complementarity in rolling over decisions.

By contrast, if the investment return is high, $r>1$, the payoff exhibits strategic substitutability in rolling over decisions. Then, the more investors withdraw from intermediary $n$, the larger is a given investor's incentive to roll over. Strategic substitutability in rolling over decisions is a 'lastman-standing effect'. In the absence of liquidation, withdrawing investors receive less than their equal share of an intermediary's total resources since the investment return is high. Thus, investors 
who roll over receive more than an equal share and thus have a greater incentive to roll over.

Zero liquidation and the last-man-standing effect can only occur with precautionary liquidity holdings. This holds in the complete-information case with a positive amount of withdrawals. Furthermore, in the case of incomplete information, there are always some investors who receive a bad signal and withdraw at the interim date. Therefore, precautionary liquidity holdings, which are absent in Morris and Shin (2000), are necessary to prevent some liquidation from taking place.

How is an investor's incentive to roll over affected by more withdrawals from another intermediary? First, there is no effect if these withdrawals are small, so the liquidity of the other intermediary suffices to serve withdrawals. Likewise, there is no effect if the withdrawals from intermediary $n$ are small because no liquidation occurs at this intermediary. Second, if withdrawals from both intermediaries are large and joint liquidation (fire sales) occurs, however, then there is strategic complementarity in rollover decisions between investors across intermediaries. The relative payoff from rolling over funding to an intermediary increases in the proportion of investors who roll over to another intermediary.

The strategic incentives of investors to roll over at the interim date are rich and nest, for example, Goldstein (2005) who studies the interaction of strategic complementarities. In a model of twin crises, the incentive of investors to withdraw from a bank as well as the incentive of speculators to attack a currency increase in the proportions of attacking speculators and withdrawing investors. Such a 'triple-decker' of strategic complementarity in rollover decision also arises here if both intermediaries liquidate some investment at the interim date. Then, each investor's incentive to withdraw from the intermediary increases in the proportion of investors who withdraw from either intermediary. However, other forms of strategic interaction are also possible. In particular, strategic substitutability in rollover decisions to the same intermediary can arise if no liquidation occurs.

Remark 1. The ex-ante portfolio choices of intermediaries determine the ex-post liquidation volume and therefore shape the strategic incentives of investors to roll over funding.

The strategic interaction between investors at the interim date is driven by the portfolio choice of intermediaries at the initial date. This link arises because an intermediary's liquidity 
holding affects the liquidation amount for some withdrawal volumes. The more liquidity is held by the intermediary, the larger the wedge between withdrawals and liquidation for any given adverse realization of the investment return. However, liquidity has no marginal benefit for low amounts of withdrawals, since no liquidation takes place. In the incomplete-information model studied here, the amount of withdrawals is tied to the realized investment return. Therefore, a low realized return leads to adverse signals for many investors and thus many withdrawals. Liquidation is positive and liquidity has a positive marginal benefit. Likewise, a high realized return leads to strong signals for many investors and thus few withdrawals. There is no liquidation and no marginal benefit of liquidity.

Solving for the equilibrium Working backwards, I start by analysing Bayesian equilibria in the incomplete-information rollover game at the interim date, which is a proper subgame. An investor's strategy is a plan of action for each private signal $x_{i}$. For any portfolio choice $\left(y_{1}, y_{2}\right)$, a profile of strategies is a Bayesian equilibrium in the subgame if the actions of each investor's strategy maximize the expected utility conditional on the private information $x_{i}$, taking as given the strategies followed by all other investors. I focus on threshold strategies, whereby an investor rolls over if and only if the private information is sufficiently good relative to a intermediary-specific threshold that depends on the portfolio choices of intermediaries:

$$
x_{i} \geq x_{n}^{*}\left(y_{n}, y_{-n}\right)
$$

Turning to the initial date, the liquidity holdings $\left(y_{1}^{*}, y_{2}^{*}\right)$ constitute a Nash equilibrium in the complete-information portfolio choice game if each intermediary's liquidity choice $y_{n}^{*}$ maximizes its objective function subject to the withdrawal threshold $x_{n}^{*}\left(y_{n}, y_{-n}\right)$, taking as given the level of liquidity held by the other intermediary $y_{-n}^{*}$.

Timeline The following time-line summarizes. 
Initial date $(t=0)$

- Endowed investors may fund intermediaries.

- Intermediaries simultaneously choose liquidity holdings $y_{n}$ and invest the remainder.

Interim date $(t=1)$

- Investor receives private information $x_{i}$ about the return on investment.

- Investors may roll over funding. A proportion $w_{n}$ withdraws.

- To serve withdrawals, intermediaries liquidate some investment $l_{n}$, if necessary.

Final date $(t=2)$

- Investment matures and its return is publicly observed.

- Investors who rolled over are paid.

- All investors consume.

\section{Equilibrium}

Analysing the case of a single intermediary first $(N=1)$, I show that introducing liquidity can restore multiple equilibria despite the standard global game refinement of slightly noisy but precise private information. In order to analyse the optimal ex-ante portfolio choice, I provide a stronger condition sufficient for overall uniqueness. The privately optimal liquidity choice is characterized and shown to be constrained efficient, so there is no role for micro-prudential regulation of liquidity. This contrasts with the case of multiple intermediaries studied in section 4 , where the private choices of intermediaries are constrained inefficient, so there is a role for macro-prudential regulation. 


\subsection{Rollover subgame}

Consider the equilibrium withdrawal behavior of investors at the interim date. Each investor uses the private information $x_{i}$ to form a posterior about the return on investment, $R_{i} \equiv \mathrm{E}\left[r \mid x_{i}\right]$, and the proportion of withdrawing investors, $W_{i} \equiv w \mid x_{i}$, both of which are derived in Appendix A.1. By definition, a 'threshold investor' is indifferent between withdrawing and rolling over upon receiving the threshold signal $x_{i}=x^{*}$, which is defined by:

$$
\mathrm{E}\left[\pi_{i} \mid x_{i}=x^{*}\right] \equiv 1
$$

where the left-hand side is the expected payoff from rolling over conditional on receiving the threshold signal $x^{*}$ and the right-hand side is the payoff from withdrawing. Because of the one-to-one mapping between the posterior mean $R_{i}$ and the private signal $x_{i}$ (see Appendix A.1), equation (9) defines an equilibrium threshold $R^{*}$, which is more convenient to use than the threshold signal $x^{*}$.

Since liquidation affects the payoff from rolling over, the cases of whether or not the threshold investor forecasts liquidation to occur are considered in turn below.

Zero liquidation forecast by threshold investor If the threshold investor forecasts zero liquidation, $W^{*} \leq y$, then the indifference condition yields:

$$
(1-y)\left(R^{*}-1\right)=0
$$

If there is maturity transformation, $y<1$, then the equilibrium threshold is $R^{*} \equiv 115$ For the consistency of this equilibrium threshold with the supposed zero liquidation forecast by the threshold investor, liquidity must be abundant. This lower bound on liquidity is derived by using the posterior about the proportion of investors who withdraw from the intermediary derived in Appendix A.1

$$
y \geq \underline{y} \equiv \Phi(\sqrt{\delta}[1-\bar{r}])<\frac{1}{2}
$$

\footnotetext{
${ }^{15}$ If there is no maturity transformation, $y=1$ or 'narrow banking', then the rollover decision of investors is irrelevant since the asset value of the intermediary is unity irrespective of the return on investment. I set $R^{*} \rightarrow-\infty$ in this case without loss of generality.
} 
where $\delta \equiv \frac{\alpha^{2}(\alpha+\gamma)}{\gamma(\alpha+2 \gamma)}$ collects precision parameters. Lemma 1 summarizes the case of zero liquidation forecast by the threshold investor:

Lemma 1. Efficient equilibrium. In the single-intermediary case, $N=1$, with abundant liquidity, $y \in[\underline{y}, 1)$, there exists a threshold equilibrium in which the threshold investor forecasts zero liquidation, $W^{*} \leq y$. For any finite precision of private information, $\gamma \in(0, \infty)$, this equilibrium prescribes an investor to roll over if and only if $R_{i} \geq R^{*}=1$, generating efficient runs on the intermediary $\left(R^{F B} \equiv 1\right)$.

The strategic incentives of investors to roll over determine the ex-post efficiency of equilibrium. In case of abundant liquidity, no liquidation is forecast by the threshold investor. As described in detail in section 2, strategic complementarity in rolling over arises for an investment return below unity, while strategic substitutability arises for a return above unity. Therefore, the unique equilibrium threshold must be unity. The privately optimal rollover rule, $R^{*}=1$, coincides with the first-best rollover rule, $R^{F B} \equiv 1$, so no coordination failure occurs among investors. Whenever the realized return on investment is below the unit return on liquidity, it is efficient not to roll over to the intermediary to terminate investment.

Threshold investor forecasts liquidation If the threshold investor forecasts some liquidation, $W^{*}>y$, then the indifference condition yields:

$$
R^{* *}=1+\chi\left(\Phi\left(\sqrt{\delta}\left[R^{* *}-\bar{r}\right]\right)-y\right)
$$

which defines $R^{* *}$ implicitly. As in Morris and Shin (2003), uniqueness of the equilibrium threshold $R^{* *}$ requires a sufficiently precise private signal $\gamma>\underline{\gamma}<\infty 16$ For the consistency of this equilibrium threshold with the supposed positive liquidation forecast by the threshold investor, liquidity must be scarce:

$$
y<\bar{y} \equiv \Phi\left(\sqrt{\delta}\left[R^{* *}-\bar{r}\right]\right)
$$

\footnotetext{
${ }^{16}$ More precisely, since the right-hand side of equation (12) is bounded, it uniqueness of the threshold is guaranteed if the slope of the left-hand side exceeds the slope of the right-hand side: $1>\sqrt{\delta} \chi^{\prime}(l) \phi\left(\sqrt{\delta}\left[R^{*}-\bar{r}\right]\right) \equiv D^{*}$, where $\phi(\cdot)$ is the probability distribution function of the standard normal distribution. Since $\phi(\cdot) \leq \frac{1}{\sqrt{2 \pi}}$ and $\chi^{\prime}(l)>0$, the finite precision of private information must be sufficiently high. If the liquidation cost function takes the simple linear form, the lower bound on the private precision $\underline{\gamma} \in(0, \infty)$ is defined as the largest $\gamma$ that solves $\delta(\gamma)=\frac{2 \pi}{\chi^{2}}$.
} 
Consequently, the ranking of equilibrium thresholds is $R^{* *}>1=R^{*}$, which also determines the ranking of bounds on liquidity, $\bar{y}>\underline{y}$. Lemma 2 summarizes the case of positive liquidation forecast by the threshold investor:

Lemma 2. Run equilibrium. In the single-intermediary case, $N=1$, with scarce liquidity, $y \in$ $[0, \bar{y})$, there exists a threshold equilibrium in which the threshold investor forecasts some liquidation, $W^{*}>y$. If private information is sufficiently precise, $\gamma \in(\underline{\gamma}, \infty)$, then this equilibrium prescribes an investor to roll over if and only if $R_{i} \geq R^{* *}>1$, as defined by equation (12). There are inefficient runs on the intermediary, $R^{* *}>R^{F B}$.

The strategic incentives of investors to roll over again determine the efficiency of equilibrium. In case of scarce liquidity, however, liquidation is forecast by the threshold investor. As described in detail in section 2, strategic complementarity in rollover decisions of investors arises globally. Hence, there is coordination failure between investors that pushes the equilibrium threshold above the efficient level, $R^{* *}>1$. Fearing that other investors refrain from rolling over funding to the intermediary, and thereby cause costly liquidation, each investor has an incentive not to roll over to the intermediary for a larger range of investment returns.

Optimal rollover decisions Lemmas 1 and 2 allow to characterize the optimal behavior of investors in the rollover subgame at the interim date. Proposition 1 follows directly and describes how the number of threshold equilibria depends on the intermediary's liquidity choice at the initial date.

Proposition 1. Multiple Bayesian equilibria in rollover subgame. Consider the rollover subgame at the interim date with a single intermediary and a sufficiently high but finite precision of private information, $\gamma \in(\underline{\gamma}, \infty)$. The number of Bayesian equilibria in threshold strategies is determined by the intermediary's liquidity choice at the initial date:

- If the intermediary holds abundant liquidity, $y \geq \bar{y}$, then the efficient equilibrium is the unique Bayesian equilibrium in the rollover subgame.

- If the intermediary holds scarce liquidity, $y<\underline{y}$, then the run equilibrium is the unique Bayesian equilibrium in the rollover subgame. 
- However, if the intermediary holds an intermediate amount of liquidity, $y \in[\underline{y}, \bar{y})$, both the efficient equilibrium and the run equilibrium exist.

The standard condition in global games does not guarantee uniqueness. That is, high but finite precision of private information is insufficient for uniqueness in the present rollover subgame once intermediaries are allowed to hold liquidity ex-ante. Apart from the usual run equilibrium when the intermediary holds scarce liquidity, there exists also an efficient equilibrium. For such an equilibrium to be present, the threshold investor must forecast zero liquidation to occur, which requires the intermediary to hold abundant liquidity. This explains the existence of different equilibria in the subgame, depending on the liquidity choice of an intermediary (see also Rochet and Vives (2004)).

Why can intermediate liquidity holdings support multiple equilibria? To gather intuition for the multiplicity result, recall the strategic incentives to roll over funding described in section 2, An important insight is that the strategic incentives of investors to roll over differ across the cases with and without liquidation (see also Remark 1 and the preceding discussion of strategic incentives). First, intermediate liquidity holdings can support an equilibrium with no liquidation forecast by the threshold investor. The strategic incentives described in detail below Lemma 1 ensure a low equilibrium threshold. Exactly at this point, the strategic incentives to roll over funding change from complementarity to substitutability. Second, intermediate liquidity holdings can also support an equilibrium with positive liquidation forecast. There are global strategic complementarities in rollover decisions of investors that lead to coordination failure and a high equilibrium threshold.

Proposition 1 nests the unique Bayesian equilibrium in Morris and Shin (2000), which corresponds to the run equilibrium in the rollover subgame, as a special case. In the absence of liquidity, $y=0<\underline{y}$, there is always positive liquidation forecast by the threshold investor. There are always some investors who receive adverse signals and do not roll over, even if the realized return on investment is high. Thus, the efficient equilibrium cannot be obtained, resulting in the run equilibrium as the unique equilibrium in the subgame.

Actual withdrawals A consequence of Proposition 1 is that some intermediate realizations of the investment return are consistent with both equilibria. To develop this point, I determine the amount 
of actual liquidation in either equilibrium, which depends on the realized return on investment.

No liquidation occurs if the liquidity holdings suffice to serve actual withdrawals, $w \mid r \leq y$, which requires a sufficiently high realized return on investment for a given ex-ante liquidity choice. The private signal conditional on the return is distributed as $x_{i} \mid r \sim \mathcal{N}\left(r, \gamma^{-1}\right)$, so the proportion of investors who withdraw is $\Phi(\sqrt{\gamma}[\bar{x}-r])$ for any signal threshold $\bar{x}$. Hence, the lower bound on the realized return on investment is, for any signal threshold $\bar{x}$ :

$$
r \geq \bar{x}+\frac{\Phi^{-1}(y)}{\sqrt{\gamma}}
$$

where $\Phi^{-1}(\cdot)$ is the inverse of the cumulative probability function of the standard normal.

First, consider the efficient equilibrium. From the posterior distribution of the return on investment (Appendix A.1), we can express the signal threshold as $x^{*} \equiv 1-\frac{\alpha}{\gamma}(\bar{r}-1)<1$. Therefore, zero actual liquidation occurs if the realized investment return is sufficiently high:

$$
r \geq r_{L} \equiv 1-\frac{\alpha}{\gamma}(\bar{r}-1)-\frac{\Phi^{-1}(y)}{\sqrt{\gamma}}
$$

Intuitively, more liquidity allows the intermediary to serve more withdrawals without liquidating investment. More withdrawals occur for lower realized investment returns, so the lower bound on the investment return decreases in the liquidity holding, $\frac{\partial r_{L}}{\partial y}<0$.

Second, consider the run equilibrium. The lower bound on the investment return is determined analogously and now depends on the implicitly defined equilibrium threshold $R^{* *}$. Zero actual liquidation occurs if the realized return on investment is sufficiently high:

$$
r \geq r_{H} \equiv R^{* *}-\frac{\alpha}{\gamma}\left(\bar{r}-R^{* *}\right)-\frac{\Phi^{-1}(y)}{\sqrt{\gamma}}
$$

For the same reasons as above, the lower bound on the investment return decreases in the liquidity holding, $\frac{\partial r_{H}}{\partial y}<0$. Since investors roll over less frequently in the run equilibrium than in the efficient equilibrium, $R^{* *}>1$, a higher realized return on investment is required to ensure zero actual liquidation in the run equilibrium, $r_{H}>r_{L}$. 
Corollary 1 expresses the multiplicity result of Proposition 1 in terms of actual liquidation at the interim date. In sum, the liquidity holding of intermediaries determines whether the threshold investor forecasts liquidation to occur, while the realized return on investment determines, for a given level of liquidity, whether liquidation actually occurs.

Corollary 1. If the intermediary holds an intermediate level of liquidity, $y \in[\underline{y}, \bar{y})$, then any realized return on investment $r \in\left[r_{L}, r_{H}\right)$ is consistent with actual liquidation (in the run equilibrium) and no liquidation (in the efficient equilibrium).

\subsection{Uniqueness refinement}

For an analysis of the private and social incentives to hold liquidity at the initial date to be meaningful, the equilibrium in the rollover subgame at the interim date must be unique. In this section, I provide a simple condition sufficient for uniqueness in the rollover subgame.

Uniqueness requires the range of intermediate liquidity holdings $[\underline{y}, \bar{y})$ to vanish. These bounds are defined in equations and (11) and (13). Since the threshold in the run equilibrium is always higher, $R^{* *}>1, \delta \rightarrow 0$ is required to ensure $\underline{y}-\bar{y} \rightarrow 0$. This means that the precision of public information relative to private information must vanish, $\frac{\alpha}{\gamma} \rightarrow 0$, which is ensured by vanishing private noise, $\gamma \rightarrow \infty$. As a consequence, the bounds on the liquidity holding that define scarcity and abundance converge, while the lower bounds on the realized return on investment required for no actual liquidation converge to the equilibrium thresholds:

$$
\begin{aligned}
\underline{y} \rightarrow \frac{1}{2} & \leftarrow \bar{y} \\
r_{L} \rightarrow R^{*} & =1 \\
r_{H} \rightarrow R^{* *} & \rightarrow 1+\chi\left(\frac{1}{2}-y\right)>1
\end{aligned}
$$

These results are summarized in Corollary 2

Corollary 2. Uniqueness refinement for the rollover subgame. Consider the rollover subgame at the interim date with a single intermediary. If fundamental uncertainty vanishes, $\gamma \rightarrow \infty$, then there exists a unique Bayesian equilibrium in threshold strategies: 
- If the intermediary holds abundant liquidity, $y \geq \frac{1}{2}$, then the efficient equilibrium occurs. Actual liquidation occurs if and only if the realized return on investment is low, $r \leq r_{L}$.

- If the intermediary holds scarce liquidity, $y<\frac{1}{2}$, then the run equilibrium occurs. Actual liquidation occurs if and only if the realized return on investment is low, $r \leq r_{H}$.

The refinement ensures uniqueness and establishes a unique link between an intermediary's liquidity choice and the withdrawal threshold of investors in the rollover subgame. Rochet and Vives (2004) obtain uniqueness away from the limit in case of delegated management. While I replicate their result under the uniqueness refinement, I also analyse the optimal liquidity choice, as studies below.

\subsection{Liquidity choice}

Using the uniqueness refinement, I analyse the intermediary's optimal liquidity choice at the initial date and derive consequences for individual fragility. See section 4 for multiple intermediaries and systemic fragility.

The liquidity choice has both marginal and discrete impact. The marginal impact is present only in the run equilibrium, where more liquidity reduces the equilibrium threshold $R^{* *}$. The discrete impact is the selection of the equilibrium in the rollover subgame as summarized by Corollary 2 , Therefore, the optimal liquidity levels in cases of abundant and scarce liquidity are derived in turn and the objective function is compared globally next. As derived in Appendix A.2, the objective function of the intermediary is the expected utility of an investor:

$$
E U(y)=y+(1-y)[F(R)+(1-F(R)) \mathrm{E}[r \mid r>R]]
$$

where $R$ is any threshold, $f(r)=\phi(\sqrt{\alpha}[r-\bar{r}])$ is the probability distribution function of the investment return with the associated cumulative distribution function $F(r)$.

The expected utility comprises the unit payoff from liquidity and the proceeds from investment. Investment is liquidated if its realized return falls short of a threshold $R$, which occurs 
with probability $F(R)$. Otherwise investment is continued, where the expected investment return conditional on continuation is $\mathrm{E}[r \mid r>R]=\bar{r}+\frac{f(R)}{\sqrt{\alpha}(1-F(R))}$.

What are the effects of changes in liquidity holdings or the equilibrium threshold on the expected utility? As derived in Appendix A.2, the marginal cost of liquidity from an ex-ante perspective is the foregone net return on investment, which is always positive:

$$
\frac{\partial E U}{\partial y}=-(1-F(R))(\mathrm{E}[r \mid r \geq R]-1)<0
$$

The marginal cost of liquidity is exacerbated by liquidating investment that shields investors from low returns. First, the expected return on investment conditional on liquidation exceeds the unit return of liquidity, where no liquidation occurs with probability $1-F(R)$. Second, the liquidation value of investment equals the unit return of liquidity, so the case of liquidation, which occurs with probability $F(R)$, drops out. Next, a lower equilibrium threshold increases expected utility, since it results in a smaller area of inefficient runs on the intermediary $[1, R]$ :

$$
\frac{\partial E U}{\partial R}=-(1-y)(R-1) \sqrt{\alpha} f(R) \leq 0
$$

Abundant liquidity, $y \geq \frac{1}{2}$, ensures the efficient equilibrium in the rollover subgame. Since the equilibrium threshold $R^{*}=1$ is independent of liquidity, there is no marginal benefit from liquidity in this subgame. Given the positive marginal cost of liquidity, the optimal amount of liquidity to implement the efficient equilibrium is the lower bound $y^{*}=\frac{1}{2}$, which yields the following expected utility:

$$
E U\left(y^{*}\right)=1+\frac{1}{2}\left[(\bar{r}-1)(1-F[1])+\frac{f[1]}{\sqrt{\alpha}}\right]>1=E U(y=1)
$$

so the intermediary prefers to implement the efficient equilibrium over narrow banking, $y=1$.

Second, consider the case of scarce liquidity $y<\frac{1}{2}$, which implies the run equilibrium $R^{* *}$. In contrast to the efficient equilibrium, the marginal benefit from liquidity is strictly positive:

$$
\frac{\partial R^{* *}}{\partial y}=-\chi^{\prime}\left(\frac{1}{2}-y\right)<0
$$


Holding more liquidity, within the feasible bounds of $y<\frac{1}{2}$, allows the intermediary to serve a larger proportion of withdrawing investors without liquidating investment. As liquidation is costly, this reduces the amount of coordination failure between investors. This lowers the equilibrium threshold and therefore increases the expected utility indirectly:

$$
\frac{\partial E U}{\partial R^{* *}} \frac{\partial R^{* *}}{\partial y}>0
$$

The intermediary's optimal amount of liquidity to implement the run equilibrium solves:

$$
y^{* *} \equiv \arg \max E U(y) \text { s.t. } R^{* *}=R^{* *}(y)
$$

If an interior solution $y^{* *} \in\left(0, \frac{1}{2}\right)$ exists, then the first-order condition balances the benefits from liquidity in terms of reducing the equilibrium threshold with the cost of liquidity in terms of foregone investment return:

$$
\overbrace{-\frac{\partial E U}{\partial y}}^{M C}=\overbrace{\frac{\partial E U}{\partial R^{* *}} \frac{\partial R^{* *}}{\partial y}}^{M B}
$$

Then, the associated level of expected utility is:

$$
E U^{* *}=1+\left(1-y^{* *}\right)\left[(\bar{r}-1)\left(1-F\left(R^{* *}\right)\right)+\frac{f\left(R^{* *}\right)}{\sqrt{\alpha}}\right]
$$

We can now characterize the optimal liquidity choice of the intermediary. Having determined the optimal liquidity choices that implement the run equilibrium and the efficient equilibrium, respectively, the intermediary compares the expected utility in either case. Therefore, the intermediary holds scarce liquidity to implement the run equilibrium in the rollover subgame if and only if $E U^{* *} \geq E U^{*}$. Let $y^{\text {global }} \equiv \arg \max \left\{E U^{*}, E U^{* *}\right\}$.

The liquidity choice trades off the foregone expected investment return with reducing the equilibrium threshold by avoiding costly liquidation. The intermediary optimally implements the run equilibrium if the liquidation cost, and therefore the benefit from liquidity, is low relative to the opportunity cost of liquidity, as summarized by Lemma 3 .

Lemma 3. Consider the case of a single intermediary and vanishing fundamental uncertainty. If 
the expected return on investment is high relative to the cost of liquidation, $\bar{r} \geq \bar{r}_{0} \equiv 1+\chi(0.5)$, then the intermediary always implements the run equilibrium in the rollover subgame, $y^{\text {global }}=y^{* *}$.

\section{Proof. See Appendix A.3.}

Furthermore, the intermediary optimally holds no liquidity, $y^{* *}=0$, if the opportunity cost of liquidity is particularly large relative to the cost of liquidation. Proposition 2 summarizes the optimal portfolio choice of the intermediary.

Proposition 2. Optimal portfolio choice. Consider the case of a single intermediary and vanishing fundamental uncertainty. If the expected return on investment is high relative to the cost of liquidation, $\bar{r} \geq 1+\chi(0.5)$, then the intermediary implements the run equilibrium in the rollover subgame. Furthermore, the optimal liquidity level takes an interior value $y^{\text {global }}=y^{* *} \in\left(0, \frac{1}{2}\right)$ that is uniquely defined by equation (21) if and only if the expected return on investment satisfies $\bar{r}_{0}<\bar{r}<\bar{r}_{H}$, where $\bar{r}_{0}$ is defined in Lemma 3 and $\bar{r}_{H}$ in the proof. However, the intermediary holds no liquidity, $y^{\text {global }}=0$, if $\bar{r} \geq \bar{r}_{H}$.

Proof. See Appendix A.4, which also proves the existence and uniqueness of $\bar{r}_{H}$.

Appendix A.4 also contains an analysis of the linear liquidation cost function. For example, I show that the larger the unit cost of liquidation, the larger the required expected return on investment $\bar{r}_{H}$ that is required for the intermediary to hold zero liquidity, $\frac{d \bar{r}_{H}}{d \chi}>0$.

I conclude this section by briefly analysing whether there is a role for government intervention. To address this question, I adopt the notion of constrained efficiency. While a direct choice of the equilibrium threshold would achieve the first-best rollover rule, such an intervention is infeasible. By contrast, the social planner is only allowed to choose the liquidity holdings and takes the optimal rollover decisions of investors at the interim date as given.

Corollary 3. Constrained efficiency. The liquidity choice of the intermediary is constrained efficient. Given the incomplete information of investors about the return on investment, a constrained social planner does not choose a different liquidity holding. As such, there is no role for a micro-prudential regulation of liquidity. 


\section{Macro-prudential liquidity regulation}

While Corollary 3 concluded that there is no role for micro-prudential liquidity regulation, I analyse multiple intermediaries $(N=2)$ in this section and show that the liquidity choices of intermediaries are constrained inefficient. This implies a role for macro-prudential liquidity regulation.

Since part of the analysis overlaps with the previous section, I focus on the case where the existence of multiple intermediaries matters for the private and social incentives to hold liquidity. That is, I focus on the run equilibrium in the rollover subgame 17 This is the relevant equilibrium for a sufficiently large expected return on investment, as shown below.

This section has three parts. I start by establishing the existence of a unique equilibrium in the rollover subgame. Next, I derive conditions sufficient for the existence of a unique private choice of liquidity at the initial date. This equilibrium is characterized by partial free-riding on the liquidity holdings of other intermediaries and leads to a constrained inefficiently large range of liquidation. As a result, I analyse the problem of a constrained planner who internalizes the beneficial effect of an intermediary's liquidity holding on other intermediaries. Since it internalizes the systemic nature of liquidity, I prefer to interpret the constrained planner as a macro-prudential authority. More liquidity held by one intermediary reduces the equilibrium threshold of another intermediary by mitigating the coordination failure between investors across intermediaries. Therefore, the macroprudential authority holds more liquidity than private intermediaries, so inefficient liquidation and runs on intermediaries occur less frequently than under laissez-faire.

\subsection{Rollover subgame}

Suppose that the threshold investor at intermediary $n$ forecasts positive liquidation, $W_{n, n}^{* * *}>y_{n}$. Furthermore, suppose that the threshold investor at intermediary $n$ also forecasts positive liquidation by the other intermediary, $W_{n,-n}^{* * *}>y_{-n}$, which is verified below 18 The threshold investor's forecast of the proportion of investors who withdraw from another intermediary is derived in Appendix A.1.

\footnotetext{
${ }^{17}$ For example, the efficient equilibrium generalizes directly, where the equilibrium threshold $R_{1}^{*}=1=R_{2}^{*}$ arises for vanishing fundamental uncertainty and abundant liquidity, $y_{1}^{*}=\frac{1}{2}=y_{2}^{*}$.

${ }^{18}$ In contrast, if the threshold investor forecasts $W_{n,-n}^{* * *} \leq y_{-n}$, then there is no effect of the presence of the other intermediary on the equilibrium threshold.
} 
For any finite precision of private information, the indifference condition of the threshold investor at intermediary $n$ yields the following best-response correspondence:

$$
R_{n}^{* * *}\left(R_{-n}^{* * *} ; y_{n}, y_{-n}\right)=1+\chi\left(W_{n, n}^{* * *}-y_{n}, W_{n,-n}^{* * *}-y_{-n}\right)
$$

While the analysis goes through for a general liquidation cost function, the linear specification $\chi_{n}\left(l_{n}+l_{-n}\right) \equiv \chi \cdot\left[l_{n}+l_{-n}\right]$ produces succinct results and is used in the remainder of the paper. For example, the unique and symmetric equilibrium threshold in the run equilibrium is identical across intermediaries, as described by Lemma 4 .

Lemma 4. Consider the case of multiple intermediaries and vanishing fundamental uncertainty. If the liquidation cost function takes the linear form of equation (5), then there exists a unique run equilibrium characterized by the equilibrium threshold:

$$
R^{* * *} \equiv 1+\chi\left(1-y_{1}-y_{2}\right)=R_{1}^{* * *}=R_{2}^{* * *}>1
$$

for scarce liquidity choices $y_{1}, y_{2} \in\left[0, \frac{1}{2}\right)$. The threshold investor at either intermediary forecasts liquidation by both intermediaries.

\section{Proof. See Appendix A.5.}

The equilibrium threshold in the run equilibrium is larger in the case of multiple intermediaries than in the case of a single intermediary, $R^{* * *}>R^{* *}>R^{F B}=1$. As stated in Remark 1 and the preceding description, two forms of strategic complementarity in rollover decisions are present in the incomplete-information setup. First, as in the case of a single intermediary, there is strategic complementarity in rollover decisions between investors of the same intermediary. This leads to coordination failure among investors of each intermediary and pushes the equilibrium threshold above the first-best level, $R^{* *}>1$.

However, there is also strategic complementarity in rollover decision between investors across intermediaries. This leads to coordination failure among investors of different intermediaries and pushes the equilibrium threshold in the run equilibrium further up, $R^{* * *}>R^{* *}$. An investor fears that other investors refuse to roll over to one intermediary, thereby increasing the extent of fire sales 
since the marginal product of liquidated investment in alternative use decreases. As a consequence, an investor has a higher incentive not to roll over to the other intermediary. Comparable to Goldstein (2005), this is a 'triple-decker' model of strategic complementarity in rollover decisions of investors.

I complete the description of the run equilibrium in the rollover subgame with two observations. First, a more restrictive lower bound on the expected return on investment, $\bar{r}>\bar{r}_{1} \equiv$ $1+\chi(0.5,0.5)=1+\chi>\bar{r}_{0}$ ensures $R^{* * *}<\bar{r}$, which is useful for constructing subsequent proofs. Second, the marginal benefit from liquidity is strictly positive in the run equilibrium:

$$
\frac{\partial R^{* * *}}{\partial y_{1}}=-\chi=\frac{\partial R^{* * *}}{\partial y_{2}}<0
$$

In the multiple-intermediary case, liquidity has a systemic nature. More liquidity held by one intermediary reduces the equilibrium threshold of another intermediary $R_{-n}^{* * *}$ by mitigating the coordination failure between investors across intermediaries. This is in addition to the result of the single-intermediary case, where more liquidity held by an intermediary also reduces the coordination failure among investors of the same intermediary and thereby lowers the equilibrium threshold $R_{n}^{* * *}$.

\subsection{Private choice of liquidity}

Turning to the initial date, I solve for the equilibrium in the portfolio choice game. Each intermediary chooses its precautionary liquidity holding by taking the equilibrium in rollover subgame $R^{* * *}\left(y_{n}, y_{-n}\right)$ into account and another intermediary's liquidity holding $y_{-n}$ as given:

$$
y_{n}^{* * *}\left(y_{-n}\right) \equiv \arg \max _{y_{n}} E U_{n}\left(y_{n}, y_{-n}\right) \text { s.t. } R^{* * *}=R^{* * *}\left(y_{n}, y_{-n}\right)
$$

If an interior solution exists, $y^{* * *}>0$, then the best response correspondence $y_{n}^{* * *}\left(y_{-n}\right)$ is defined by the first-order condition:

$$
\underbrace{-\frac{\partial E U_{n}}{\partial y_{n}}}_{M C}=\underbrace{\frac{\partial E U_{n}}{\partial R_{n}^{* * *}} \frac{\partial R_{n}^{* * *}\left(y_{n}, y_{-n}\right)}{\partial y_{n}}}_{M B}
$$

where the private choice of liquidity again balances the private marginal benefit from liquidity (avoiding costly liquidation and thus reducing the equilibrium threshold) with the private marginal 
cost (foregone investment return).

In Appendix A.6. I derive conditions on the expected return on investment, $\bar{r}_{L} \leq \bar{r} \leq \bar{r}_{H}$, that are sufficient for the the existence of a best-response function $y_{n}^{* * *}\left(y_{-n}\right)$. A sketch of the argument follows. Since the objective function $E U_{n}$ is globally concave in the level of liquidity $y_{n}$ when evaluated at the equilibrium threshold $R^{* * *}\left(y_{n}, y_{-n}\right)$, there exists at most one solution. Next, the upper and lower bounds on the expected return on investment ensure the existence of a solution, where the upper bound is identical to $\bar{r}_{H}$, which guaranteed an interior solution of $y^{* *}$ in the single-intermediary case.

As derived in Appendix A.7, the private choices of liquidity are strategic substitutes. If another intermediary holds more liquidity, the liquidation cost of a given intermediary is reduced. The fire sales effect is less pronounced since the marginal product of liquidated investment in alternative use is higher. Since holding liquidity is costly (foregone investment return), the given intermediary optimally reduces its liquidity holding. That is, intermediaries free-ride on the liquidity held by other intermediaries.

However, another intermediary's liquidity holding is only partially useful. While other liquidity holdings help to reduce the cost from liquidation by mitigating the fire sale effect, only the liquidity held by an intermediary can be used to serve withdrawing investors and to prevent costly liquidation. For this reason, liquidity holdings of intermediaries are only partial substitutes, despite the full symmetry in their effect on the equilibrium threshold in the run equilibrium:

$$
\frac{d y_{n}^{* * *}}{d y_{-n}} \in(-1,0)
$$

There exists a unique crossing of best response functions because the slope of the best-response function lies strictly within the unit circle and the best response function is symmetric. Therefore, the private choice of liquidity is identical across intermediaries, $y_{n}^{* * *} \equiv y^{* * *}$. Since the previous bounds on the expected return on investment are sufficient for $y^{* * *} \in\left[0, \frac{1}{2}\right)$, the private choice of liquidity is implicitly given by $\frac{d E U_{n}}{d y_{n}}\left(y^{* * *}, y^{* * *}\right)=0$.

To evaluate the consequences of free-riding on other liquidity holdings, I compare the range 
of ex-post inefficient liquidation in the multiple-intermediary case to the single-intermediary-case. Ex-post inefficient liquidation, which is a consequence of incomplete information, always occurs in the run equilibrium, $R^{* *}>R^{F B}$. In this statement, 'inefficient' refers to a comparison with the first-best liquidation rule. It is critical to emphasize that the welfare criterion adopted in this paper is not first-best but constrained efficiency from an ex-ante perspective. Therefore, I compare the extent of ex-post inefficient liquidation across various choices of ex-ante liquidity holdings. Then, exante constrained inefficiency occurs whenever 'excessive' liquidation occurs in the run equilibrium, which is defined as $R>R^{S P}$. In a nutshell, inefficient refers to (the absence of) first-best, while excessive refers to (the absence of) second-best.

Proposition 3 summarizes the private choice of liquidity and its welfare properties. It can be shown that the free-riding on liquidity holdings leads to an excessive ex-post liquidation in the run equilibrium, $R^{* * *}>R^{* *}$. Since the range of inefficient liquidation $[1, R]$ is larger in the multipleintermediary case than in the single-intermediary case, the private portfolio choice is constrained inefficient from an ex-ante perspective.

Proposition 3. Free-riding and constrained inefficiency. Consider the case of multiple intermediaries and vanishing fundamental uncertainty. If the expected return on investment takes an intermediate value, $\bar{r} \in\left[\bar{r}_{L}, \bar{r}_{H}\right]$, then there exists a unique and symmetric equilibrium. This equilibrium is characterized by a private choice of liquidity at the initial date, $y_{1}^{* * *}=y_{2}^{* * *} \equiv y^{* * *} \in\left[0, \frac{1}{2}\right)$, that implements the run equilibrium in the rollover subgame between investors at the interim date. Each investor rolls over funding to the intermediary if and only if $R_{i} \geq R^{* * *}$. The quantities are implicitly defined by:

$$
\begin{aligned}
R^{* * *} & =1+\chi\left(1-2 y^{* * *}\right)>1 \\
\chi\left(1-y^{* * *}\right)\left(R^{* * *}-1\right) & =\frac{1}{\alpha}+(\bar{r}-1) \frac{1-F\left(R^{* * *}\right)}{\sqrt{\alpha} f\left(R^{* * *}\right)}
\end{aligned}
$$

This equilibrium is characterized by partial free-riding on the liquidity of other intermediaries. As a result, the coordination failure among investors across intermediaries leads to excessive liquidation ex-post and renders the private choice of liquidity as constrained inefficient:

$$
R^{* * *}>R^{* *}
$$


The constrained inefficiency from an ex-ante perspective is related to the strategic complementarity in rollover decisions between investors across intermediaries. Fearing that investors refuse to roll over to another intermediary, thereby exacerbating the fire sale effect of joint liquidation, investors have a greater incentive not to roll over funding to their intermediary. However, an intermediary does not consider the beneficial impact of its private choice of liquidity on other intermediaries, which would reduce the coordination failure between investors across intermediaries. Instead, an intermediary free-rides on the liquidity held by other intermediaries in the system and holds insufficient liquidity itself. Therefore, excessive liquidation occurs and the private liquidity holdings are constrained inefficient.

\subsection{Social choice of liquidity}

A constrained planner chooses the liquidity holdings of both intermediaries at the initial date, taking the optimal rollover decision of investors at the interim date into account. In contrast to an intermediary, the planner internalizes the benefit of one intermediary's liquidity holding on another intermediary. Since the constrained planner captures these systemic effects of liquidity, my preferred interpretation is that of a macro-prudential authority.

The social choice of liquidity that implements the run equilibrium, $y_{k}^{S P} \in\left[0, \frac{1}{2}\right)$, maximizes the social welfare function $S W F$ :

$$
\left(y_{1}^{S P}, y_{2}^{S P}\right) \equiv \arg \max _{y_{1}, y_{2}} S W F \equiv E U_{1}+E U_{2} \text { s.t. } R_{k}^{S P}=R^{S P}\left(y_{1}, y_{2}\right)
$$

If an interior solution exists, it is characterized by the first-order condition:

$$
\overbrace{-\frac{\partial E U_{n}}{\partial y_{n}}}^{S M C}=\overbrace{\frac{\partial E U_{n}}{\partial R_{n}^{S P}} \frac{\partial R_{n}^{S P}}{\partial y_{n}}+\frac{\partial E U_{-n}}{\partial R_{-n}^{S P}} \frac{\partial R_{-n}^{S P}}{\partial y_{n}}}^{S M B}
$$

The social choice of liquidity balances the social marginal cost of liquidity (foregone investment return) with the social marginal benefits from liquidity (lower equilibrium thresholds by avoiding costly liquidation). The private and social marginal costs of liquidity coincide because the opportu- 
nity cost of holding liquidity is unchanged. By contrast, the social marginal benefit from liquidity exceeds the private marginal benefit. Apart from the beneficial effect of liquidity on the investors of one intermediary $\left(\partial R_{n}^{S P} / \partial y_{n}<0\right)$, which is identical to the private marginal benefit from liquidity, the planner also considers the beneficial effect on the other intermediary's investors $\left(\partial R_{-n}^{S P} / \partial y_{n}<0\right)$. More liquidity allows an intermediary to serve more withdrawing investors and therefore mitigates the effect of fire sales. Therefore, the marginal product of liquidated investment in alternative use is higher, which reduces the coordination failure between investors across intermediaries.

The optimization problem is fully symmetric. From a social perspective, there is full substitutability between liquidity held at one intermediary and that held at another in order to reduce the equilibrium threshold $R_{n}^{S P}=R^{S P}=1+\chi\left[1-y_{1}^{S P}-y_{2}^{S P}\right]$. Furthermore, both first-order conditions yield the same condition, equation (33). Therefore, only the total amount of liquidity is determined $y_{\text {total }}^{S P} \equiv y_{1}^{S P}+y_{2}^{S P}$. I adopt the convention that $y_{n}^{S P} \equiv \frac{y_{\text {total }}^{S P}}{2}$. As shown in Appendix A.8, a unique social liquidity choice exists if the expected return on investment takes again an intermediate value, $\bar{r} \in\left[\bar{r}_{L}, \bar{r}_{H}^{S P}\right]$.

The macro-prudential authority holds zero liquidity for a smaller range of parameters than a private intermediary. That is, the upper bound for the social choice of liquidity is less restrictive that the upper bound for the private choice of liquidity, $\bar{r}_{H}^{S P}>\bar{r}_{H}$. Intuitively, the macro-prudential authority is more reluctant to hold zero liquidity as it considers the systemic benefits from liquidity, not only the individual benefits. If the expected return on investment follows $\bar{r} \in\left[\bar{r}_{H}, \bar{r}_{H}^{S P}\right]$, then the run equilibrium is implemented. While the intermediary optimally holds zero liquidity, $y^{* * *}=0$, the macro-prudential authority holds some liquidity, $y^{S P}>0$.

Proposition 4 summarizes the social choice of liquidity and compares it to the private choice of liquidity. The more restrictive bounds on the expected return on investment are used to allow comparison.

Proposition 4. Social liquidity choice and constrained efficiency. Consider the case of multiple intermediaries and vanishing fundamental uncertainty. If the expected return on investment takes an intermediate value, $\bar{r} \in\left[\bar{r}_{L}, \bar{r}_{H}\right]$, then there exists a unique equilibrium. This equilibrium is characterized by a social choice of liquidity $y_{\text {total }}^{S P} \in[0,1)$ that optimally implements the run 
equilibrium in the rollover subgame. Each investor rolls over to the intermediary if and only if $R_{i} \geq R^{S P}=1+\chi\left(1-y_{\text {total }}^{S P}\right)>1$, where the social choice of liquidity is the unique solution of:

$$
\chi^{2}\left(2-y_{\text {total }}^{S P}\right)\left(1-y_{\text {total }}^{S P}\right)=\frac{1}{\alpha}+\frac{\bar{r}-1}{\sqrt{\alpha}} \frac{1-F\left[1+\chi\left(1-y_{\text {total }}^{S P}\right)\right]}{f\left[1+\chi\left(1-y_{\text {total }}^{S P}\right)\right]}
$$

A macro-prudential authority holds more liquidity than private intermediaries. It also generates a smaller range of ex-post inefficient liquidation:

$$
\begin{aligned}
y_{\text {total }}^{S P} & >2 y^{* * *} \\
1<R^{S P} & <R^{* *}<R^{* * *}
\end{aligned}
$$

\section{Proof. See Appendix A.8}

A macro-prudential authority takes the systemic nature of liquidity into account. As a result, the social choice of liquidity exceeds the private choice, because the former internalizes the social marginal costs of liquidation due to fire sales (that is the social marginal benefit from liquidity). Therefore, the macro-prudential authority mitigates the coordination failure between investors across intermediaries and reduces the range of ex-post inefficient liquidation. The difference between the social and private choices of liquidity, $y^{S P}-y^{* * *}$, is interpreted as a macro-prudential liquidity buffer.

\section{Discussion}

The purpose of this section is threefold. I start by discussing some assumptions of the model and their impact on the results. Next, I also argue that this micro-founded setup is suitable for an analysis of macro-prudential regulation more broadly and highlight avenues of further work. Finally, I relate of my findings to the regulatory debate of Basel III. 


\subsection{Model assumptions and extensions}

First, I analyse the welfare implications in case of two intermediaries. This can be generalized to any finite number of intermediaries without losing either the strategic substitutability in private choices of liquidity or their welfare properties. While the strategic aspect of liquidity choices vanishes in the limiting case of a continuum of intermediaries, the welfare result prevails.

Next, I consider an exogenous debt contract whereby an investor receives a unit payment upon not rolling over. This approach is similar to Dasgupta (2004) and Shapiro and Skeie (2013). It ensures the viability of intermediaries at the interim date since the promised payment does not exceed the liquidation value. I do not attempt to endogenize the debt contract in the present paper, but this could be achieved by assuming idiosyncratic liquidity risk that creates demand for liquidity at the interim date as in Diamond and Dybvig (1983). However, I do endogenize the portfolio choice of intermediaries, which improves upon Morris and Shin (2000) who explicitly abstract from both the optimal contract design and the ex-ante portfolio choice of intermediaries.

The strategic interaction between investors arises from costly liquidation of investment due to diminishing marginal product in alternative use, which contrasts with Goldstein and Pauzner (2005), where it arises since the promised interim-date payment exceeds the liquidation value of investment. The present setup allows to analyse not only the ex-ante portfolio choice of intermediaries subject to rollover risk, but also the systemic nature of liquidity in case of multiple intermediaries and fire sales.

Third, investors deposit with a single intermediary for simplicity. However, this result can allow for a diversification of intermediaries with whom investors deposit. For concreteness, consider the case in which a proportion $\omega$ of investor deposits with both intermediaries. Then, the difference in the objective functions of the intermediary and the macro-prudential authority shrinks but the welfare result prevails. While the objective functions coincide in the extreme case of $\omega=1$, this scenario is unlikely because some investors are unsophisticated or face high costs of diversifying their deposit. 


\subsection{Relation to regulatory debate}

I develop a model of financial intermediaries that optimally choose their portfolio composition before facing rollover risk in their funding. Because assets are jointly liquidated in a fire sale, private choices of liquidity are strategic substitutes, so each intermediary free-rides on the liquidity of other intermediaries. This set-up results in constraint inefficient liquidity choices of intermediaries and creates a role for macro-prudential regulation. A constrained planner, preferably interpreted as a macro-prudential authority, internalizes the systemic nature of liquidity and requires intermediaries to hold more liquidity than under laissez faire. Furthermore, the macro-prudential authority holds positive liquidity for a larger range of parameters than a private intermediary, which is particularly welfare-improving whenever fire sales are severe, such as during a financial crisis.

There are different options for a macro-prudential authority to require intermediaries to hold larger amounts of liquidity. Two of these are currently discussed and implemented within the endorsed Basel III framework. The first option is to require intermediaries to hold a short-term liquidity buffer against unforeseen liquidity outflows. Translated into the model setup, this Liquidity Coverage Ratio (LCR) rule requires intermediaries to hold more liquidity in the initial period, that is before shocks are realized (and investors receive their private signal about the solvency of the intermediary) 19 In the words of the Basel Committee on Banking Supervision (2013): "It does this by ensuring that a bank has an adequate stock of unencumbered high-quality liquid assets (HQLA) that can be converted into cash easily and immediately in private markets to meet its liquidity needs for a 30 calendar day liquidity stress scenario." The additional liquidity holdings required from intermediaries by the macro-prudential authority (Proposition 4) are therefore best interpreted and implemented in the form of a LCR.

This leads to the question of the optimal implementation of the LCR. One option is to request each intermediary to hold additional liquidity to offset the effect of liquidity free-riding. Another option is to create a systemic liquidity fund which all intermediaries contribute to. While another intermediary's liquidity can be used to dampen the effects of a fire-sale, investors who withdraw can only be served with the liquidity held by an intermediary. Therefore, another intermediary's

\footnotetext{
${ }^{19}$ To match the LCR, the duration between the initial and final date is required to be one month.
} 
liquidity is only a partial substitute. Hence, this suggests that the preferable way to implement a macro-prudential liquidity buffer is in the form of increased liquidity requirements for individual intermediaries.

In contrast to the LCR, the Net Stable Funding Ratio (NSFR) rule proposed by Basel III restricts the availability of demandable debt instruments to investors. Thus, it directly addresses the ratio of stable to unstable funding of the intermediary. The NSFR is computed as the ratio of the available amount of stable funding (ASF) to the required amount of stable funding (RSF) and should always exceed $100 \%$. Unsecured wholesale funding, as discussed in this paper, is attributed a weight of $50 \%$ in the ASF. As a result, the NSFR is likely to impose a strong restriction on the optimal funding structure of intermediaries. However, the present model is more suitable for analysing the LCR to which it links directly. By including long-term debt and equity in the analysis (see also discussion above), an extension of this model could inform the policy debate on the NSFR more directly.

Finally, a key feature of the financial crisis of 2007-09 was the specific role of information. After the insolvency of Lehman Brothers and the subsequent insolvency of the Reserve Primary Fund, the fear of further contagion triggered substantial liquidity outflows from many money market mutual funds (see Schmidt et al. (2013)) that, in turn, drew liquidity from the banking system. The global games approach of this paper appears to be a very suitable modeling choice: coordination between investors of one intermediary, as well as between investors across intermediaries, is at the heart of the analysis presented in this paper (recall Remark 1 and the preceding description of the strategic incentives of investors to roll over funding).

\section{Conclusion}

This paper studied rollover risk in the wholesale funding market when intermediaries can hold liquidity ex-ante and are subject to fire sales ex-post. I showed that the presence of liquidity, which drives a wedge between the amount of withdrawals and the liquidation volume, restores multiple equilibria - even if a global game refinement is used. Apart from the usual equilibrium 
with coordination failure and a high equilibrium threshold, a constrained efficient equilibrium with a low equilibrium threshold exists for sufficiently high levels of liquidity. Liquidity holdings serve withdrawing investors and therefore support an equilibrium in which the threshold investor forecasts no liquidation to take place. I provide a simple uniqueness refinement to characterize the privately optimal liquidity choice.

Furthermore, I explored fire sales in a simple set-up with two intermediaries, whereby one intermediary's liquidation volume increases the liquidation costs of another intermediary. The positive implication of fire sales is that the liquidity holdings are partial substitutes. As a result, intermediaries free-ride on each other's liquidity holdings, causing excessive liquidation of productive investment. The normative implication of fire sales is that intermediaries hold insufficient liquidity relative to a constrained planner. Such a planner is best interpreted as a macro-prudential authority, since it internalizes the systemic nature of liquidity, leading to a smaller range of inefficient liquidation.

This framework provides a natural laboratory for studying macro-prudential policies in a micro-founded setting more generally. There are other elements relevant to the conduct of macroprudential regulation omitted in this framework, such as capital requirements, portfolio diversification, or penalties on early withdrawals. These are all exciting avenues for subsequent research. 


\section{References}

Allen, F. and Gale, D. (1994), 'Limited market participation and volatility of asset prices', American Economic Review 84(4), 933-55.

Angeletos, G.-M., Hellwig, C. and Pavan, A. (2006), 'Signaling in a global game: Coordination and policy traps', Journal of Political Economy 114(3), 452-484.

Angeletos, G.-M. and Werning, I. (2006), 'Crises and prices: Information aggregation, multiplicity, and volatility', The American Economic Review 96(5), 1720-1736.

Basel Committee on Banking Supervision (2013), Basel III: The Liquidity Coverage Ratio and liquidity risk monitoring tools, Technical report, Bank for International Settlements.

Campbell, J. Y., Giglio, S. and Pathak, P. (2011), 'Forced sales and house prices', American Economic Review 101(5), 2108-31.

Carlsson, H. and van Damme, E. (1993), 'Global games and equilibrium selection', Econometrica 61(5), 989-1018.

Dasgupta, A. (2004), 'Financial contagion through capital connections: A model of the origin and spread of bank panics', Journal of the European Economic Association 2(6), 1049-1084.

Diamond, D. and Dybvig, P. (1983), 'Bank runs, deposit insureance and liquidity', Journal of Political Economy 91, 401-419.

Eisenbach, T. M. (2013), 'Rollover risk as market discipline: A two-sided inefficiency', Federal Reserve Bank of New York Staff Report No. 597.

Farhi, E. and Tirole, J. (2012), 'Collective moral hazard, maturity mismatch, and systemic bailouts', American Economic Review 102(1), 60-93.

Gale, D. (2010), 'Capital regulation and risk sharing', International Journal of Central Banking 6(3), 187-204.

Goldstein, I. (2005), 'Strategic complementarities and the twin crises', Economic Journal 115, 368390. 
Goldstein, I. and Pauzner, A. (2005), 'Demand deposit contracts and the probability of bank runs', Journal of Finance 60(3), 1293-1327.

Gromb, D. and Vayanos, D. (2002), 'Equilibrium and welfare in markets with financially constrained arbitrageurs', Journal of Financial Economics 66(2), 361-407.

Grossman, S. J. and Stiglitz, J. E. (1980), 'On the impossibility of informationally efficient markets', American Economic Review 70(3), 393-408.

Hellwig, C., Mukherji, A. and Tsyvinski, A. (2006), 'Self-fulfilling currency crises: The role of interest rates', American Economic Review 96, 1769-1787.

Hellwig, C. and Veldkamp, L. (2009), 'Knowing what others know: Coordination motives in information acquisition', Review of Economic Studies 76, 223-251.

Huang, R. and Ratnovski, L. (2011), 'The dark side of bank wholesale funding', Journal of Financial Intermediation 20(2), 248-263.

Kiyotaki, N. and Moore, J. (1997), 'Credit cycles', Journal of Political Economy 105, 211-248.

Martin, A., Skeie, D. and von Thadden, E.-L. (2013), 'Repo runs', Discussion Paper Series of SFB/TR 15, No. 448 .

Morris, S. and Shin, H. S. (2000), 'Rethinking multiple equilibria in macroeconomic modelling', Cowles Foundation Discussion Paper 1260 .

Morris, S. and Shin, H. S. (2003), 'Global games: Theory and applications'.

Morris, S. and Shin, H. S. (2010), 'Illiquidity component of credit risk', Mimeo, Princeton University

Rochet, J.-C. and Vives, X. (2004), 'Coordination Failures and the Lender of Last Resort: Was Bagehot Right After All?', Journal of the European Economic Association 2(6), 1116-1147.

Schmidt, L., Timmermann, A. and Wermers, R. (2013), 'Runs on money market mutual funds', Mimeo . 
Shapiro, J. and Skeie, D. (2013), 'Information management in banking crises', CEPR Discussion Paper 9612.

Shleifer, A. and Vishny, R. W. (1992), 'Liquidation values and debt capacity: A market equilibrium approach', The Journal of Finance 47(4), 1343-1366.

The Basel Committee (2010a), 'Basel III: A global regulatory framework for more resilient banks and banking systems'.

The Basel Committee (2010b), 'Basel III: International framework for liquidity risk measurement, standards and monitoring'.

Uhlig, H. (2010), 'A model of a systemic bank run', Journal of Monetary Economics 57, 78-96.

Vives, X. (2013), 'Strategic complementarity, fragility, and regulation', IESE Working Paper 928.

Wagner, W. (2009), 'Efficient asset allocations in the banking sector and financial regulation', International Journal of Central Banking 5(1), 75-95.

Wagner, W. (2011), 'Systemic liquidation risk and the diversity-diversification trade-off', Journal of Finance 66(4), 1141-1175. 


\section{A Appendix}

\section{A.1 Posterior distributions}

Return on investment The posterior distribution of the return on investment is also normal. The posterior precision is the sum of the prior precisions and the precision of the private information. The mean is a weighted average of the prior and the private signal with the respective precisions as weights.

$$
r \mid x_{i} \sim \mathcal{N}\left(\frac{\alpha \bar{r}+\gamma x_{i}}{\alpha+\gamma}, \frac{1}{\alpha+\gamma}\right)
$$

The ratio of the precision of the prior (public signal) relative to the private signal, $\frac{\alpha}{\gamma}$, determines the extent to which the posterior mean depends on the private signal. The more precise the private signal relatively to the prior, the more the posterior is determined by the private signal. As private noise vanishes, $\gamma \rightarrow \infty$, the posterior mean converges to the private signal.

Proportion of investors who withdraw from the same intermediary Using a law of large numbers, the posterior proportion of investors who withdraw from intermediary $n$ is:

$$
\begin{aligned}
W_{i n} & =\Phi\left(\sqrt{\delta}\left[R_{n}^{*}-\bar{r}\right]+\sqrt{\frac{\gamma(\alpha+\gamma)}{\alpha+2 \gamma}}\left[R_{n}^{*}-R_{i}\right]\right) \\
\delta & \equiv \frac{\alpha^{2}(\alpha+\gamma)}{\gamma(\alpha+2 \gamma)}
\end{aligned}
$$

where $\Phi(\cdot)$ is the cumulative distribution function of the standard normal and $\delta$ summarizes precision parameters. Therefore, the threshold investor has the following posterior:

$$
\begin{aligned}
W_{n}^{*} & \left.\equiv W_{i}\right|_{x_{i}=x^{*}}=\Phi\left(z_{1 n}\right) \\
z_{1 n} & \equiv \sqrt{\delta}\left[R_{n}^{*}-\bar{r}\right]
\end{aligned}
$$

If private noise vanishes, $\gamma \rightarrow \infty$, then $\delta \rightarrow 0$ and $W_{n}^{*} \rightarrow \frac{1}{2}$. 
Proportion of investors who withdraws from another intermediary In the case of multiple banks, an investor needs to forecast the proportion of investors who withdraw from another intermediary:

$$
\begin{aligned}
W_{i, n,-n} & =\Phi\left(\sqrt{\delta}\left[R_{-n}^{*}-\bar{r}\right]+\sqrt{\frac{\gamma(\alpha+\gamma)}{\alpha+2 \gamma}}\left[R_{-n}^{*}-R_{i n}\right]\right) \\
\left(W_{n,-n}\right)^{*} & \left.\equiv W_{i, n,-n}\right|_{x_{i}=x_{n}^{*}}=\Phi\left(z_{2 n}\right) \\
z_{2 n} & \equiv \sqrt{\delta}\left[R_{-n}^{*}-\bar{r}\right]+\sqrt{\delta} \frac{\gamma}{\alpha}\left[R_{-n}^{*}-R_{n}^{*}\right]
\end{aligned}
$$

\section{A.2 Derivation of expected utility}

Consider the case of a single intermediary, $n=1$. As private noise vanishes, $\gamma \rightarrow \infty$, the realized proportion of investors who withdraw from the intermediary at the interim date is:

$$
w^{*}(r)=\Phi\left(\frac{\alpha}{\sqrt{\gamma}}[R-\bar{r}]+\sqrt{\gamma}[R-r]\right) \rightarrow\left\{\begin{array}{ccc}
0 & r>R \\
\frac{1}{2} & \text { if } & r=R \\
1 & & r<R
\end{array}\right.
$$

for any equilibrium threshold $R$. Therefore, there is no (full) liquidation of investment if the return on investment is above (below) the threshold $R$. Investors receive the continuation payoff $c_{2}$ or a unit liquidation payoff. These payoffs follow from the timing of liquidation costs, which occur at the final date as in Morris and Shin (2000). This timing of liquidation costs is implied by a lender-of-last-resort policy, for instance. Adding up, the expected utility is:

$$
\begin{aligned}
E U(y) & =\int_{-\infty}^{R} \phi(\sqrt{\alpha}[r-\bar{r}]) d r+\int_{R}^{\infty}[y+(1-y) r] \phi(\sqrt{\alpha}[r-\bar{r}]) d r \\
& =y+(1-y)\left[F(R)+(1-F(R)) \bar{r}+\frac{f(R)}{\sqrt{\alpha}}\right]
\end{aligned}
$$


The partial derivatives of the expected utility are:

$$
\begin{aligned}
\frac{\partial E U}{\partial y} & =-[1-F(R)](\bar{r}-1)-\frac{f(R)}{\sqrt{\alpha}}<0 \\
\frac{\partial E U}{\partial R} & =-(1-y)(R-1) \sqrt{\alpha} f(R) \leq 0 \\
\frac{\partial E U}{\partial y \partial R} & =(R-1) \sqrt{\alpha} f(R) \geq 0 \\
\frac{\partial^{2} E U}{\partial R^{2}} & =-(1-y) \sqrt{\alpha} f(R)[1+\alpha(R-1)(\bar{r}-R)] \leq 0 \\
\frac{\partial^{2} E U}{\partial y^{2}} & =0
\end{aligned}
$$

\section{A.3 Proof of Lemma 3}

The optimal liquidity choice to implement the efficient equilibrium is $y^{*}=\frac{1}{2}$, which yields:

$$
E U\left(y^{*}\right)=1+\frac{1}{2}\left[(\bar{r}-1)(1-F[1])+\frac{f[1]}{\sqrt{\alpha}}\right]
$$

If $y=0$, which may not be optimal, then inefficient equilibrium is implemented. The expected utility in this case is:

$$
E U(y=0)=1+(\bar{r}-1)(1-F[1+\chi(0.5)])+\frac{f[1+\chi(0.5)]}{\sqrt{\alpha}}
$$

Thus, we have that $E U(y=0)>E U\left(y^{*}\right)$ if two conditions hold. First, $\Phi(\sqrt{\alpha}[\bar{r}-1-\chi(0.5)])>$ $0.5 \Phi(\sqrt{\alpha}[\bar{r}-1])$. Since the right-hand side of this equation is smaller than one half, $\bar{r} \geq 1+\chi(0.5)$ suffices to ensure this constraint. Second, $\Phi(\sqrt{\alpha}[\bar{r}-1-\chi(0.5)])>0.5 \Phi(\sqrt{\alpha}[\bar{r}-1])$. Since $\phi(\cdot)$ is the largest the closer the argument is to zero, the bound on the expected return is again sufficient for this constraint.

\section{A.4 Proof of Proposition 2}

Rewriting equation (22) yields $L H S \equiv(1-y) \chi\left(\frac{1}{2}-y\right) \chi^{\prime}\left(\frac{1}{2}-y\right)=\frac{1}{\alpha}+\frac{(\bar{r}-1) \Phi\left(\sqrt{\alpha}\left[\bar{r}-R^{* *}\right]\right)}{\sqrt{\alpha} \phi\left(\sqrt{\alpha}\left[\bar{r}-R^{* *}\right]\right)} \equiv R H S$, where $R^{* *}=1+\chi(0.5-y)$. 
Below I show that the LHS is smaller than the RHS at the upper bound and that the LHS (RHS) decreases (increases) in the liquidity level $y$ if the lower bound on the expected return on investment is maintained. First, observe that $L H S \rightarrow 0<\frac{1}{\alpha}+\frac{(\bar{r}-1) \Phi(\sqrt{\alpha}[\bar{r}-1])}{\sqrt{\alpha} \phi(\sqrt{\alpha}[\bar{r}-1])} \leftarrow R H S$ as $y \rightarrow 0.5$. Second, $L H S^{\prime}(y)=-\chi \chi^{\prime}-(1-y)\left[\left(\chi^{\prime}\right)^{2}+\chi \chi^{\prime \prime}\right]<0$. Third, introduce $\Lambda(R) \equiv \frac{1-\Phi(\sqrt{\alpha}[R-\bar{r}])}{\phi(\sqrt{\alpha}[R-\bar{r}])}>0$, so $\Lambda^{\prime}(R)=-\sqrt{\alpha}-\alpha(\bar{r}-R) \Lambda(R)$. Thus, $R H S^{\prime}(y)=-\frac{\bar{r}-1}{\sqrt{\alpha}} \chi^{\prime}(0.5-y) \Lambda^{\prime}\left(R^{* *}\right)$. Therefore, $R H S^{\prime}(y)>0$ if $\bar{r}>R^{* *}$, which is again ensured by the condition $\bar{r} \geq 1+\chi(0.5)$ that we already used in the proof of Lemma 3

As a consequence, the corner solution $y^{* *}=0$ is the optimal liquidity choice of the intermediary if $L H S(0) \leq R H S(0)$, which imposes the constraint on the liquidation cost function:

$$
\chi(0.5) \chi^{\prime}(0.5) \leq \frac{1}{\alpha}+\frac{\Phi(\sqrt{\alpha}[\bar{r}-1-\chi(0.5)])}{\sqrt{\alpha} \phi(\sqrt{\alpha}[\bar{r}-1-\chi(0.5)])}
$$

Define $\bar{r}_{H}$ as the value of $\bar{r}$ for which condition (55) holds with equality.

Since the left-hand side is independent of the expected return on investment, the proof of the existence and uniqueness of $\bar{r}_{H}$ can be completed for the linear liquidation cost function without loss of generality. If the liquidation cost function takes the simple linear form, this constraint simplifies to:

$$
\frac{\chi^{2}}{2} \leq \frac{1}{\alpha}+\frac{(\bar{r}-1) \Phi\left(\sqrt{\alpha}\left[\bar{r}-1-\frac{\chi}{2}\right]\right)}{\sqrt{\alpha} \phi\left(\sqrt{\alpha}\left[\bar{r}-1-\frac{\chi}{2}\right]\right)}
$$

Then, $\bar{r}_{H}$ exists and is unique. First, as $\bar{r} \rightarrow \infty$, the left-hand side (LHS) of equation (62) is positive and finite and the right-hand side (RHS) goes to infinity. Next, as the expected return converges to its minimum $\bar{r} \rightarrow 1+\frac{\chi}{2}, L H S=\frac{\chi^{2}}{2}$ and $R H S \rightarrow \frac{1}{\alpha}+\frac{\sqrt{2 \pi} \chi}{4 \sqrt{\alpha}}$. A necessary condition is $\operatorname{LHS}\left(\bar{r}=1+\frac{\chi}{2}\right)>\operatorname{RHS}\left(1+\frac{\chi}{2}\right)$, which yields:

$$
\chi \sqrt{\alpha}>\sqrt{\frac{\pi}{8}}+\sqrt{\frac{\pi}{8}+2}
$$

where the right-hand side reflects the specifics of the probability distribution function. Condition (57) is satisfied if the precision of the public information is sufficiently high, $\alpha>\alpha_{L} \equiv$ 
$\left(\frac{\sqrt{\frac{\pi}{8}}+\sqrt{\frac{\pi}{8}+2}}{\chi}\right)^{2}$. Third, the right-hand side increases in the expected investment return:

$$
\frac{\partial R H S}{\partial \bar{r}}=(\bar{r}-1) \sqrt{\alpha}+\left(1+\alpha\left[\bar{r}-1-\frac{\chi}{2}\right]\right) \frac{\Phi(z)}{\phi(z)}>0
$$

where $z \equiv \sqrt{\alpha}\left[\bar{r}-1-\frac{\chi}{2}\right]$ is a short hand. Taking all of the three steps together, there exists a unique $\bar{r}_{H}$ as claimed.

As for the dependence of $\bar{r}_{H}$ on $\chi$, total differentiation yields:

$$
\frac{d \bar{r}_{H}}{d \chi}=\frac{\chi-\frac{\partial R H S}{\partial \chi}}{\frac{\partial R H S}{\partial \bar{r}}}
$$

To evaluate this, $\frac{\partial R H S}{\partial \chi}$ is required:

$$
\frac{\partial R H S}{\partial \chi}=-\frac{\bar{r}_{H}-1}{\sqrt{\alpha}} \frac{1}{2}\left(1+\alpha \frac{\Phi(z)}{\phi(z)}\left[\bar{r}_{H}-1-\frac{\chi}{2}\right]\right)<0
$$

Therefore, $\frac{d \bar{r}_{H}}{d \chi}>0$ as claimed.

\section{A.5 Proof of Lemma 4}

This proof partially builds on Goldstein (2005) but proceeds differently 20

First, observe that the cdf of the standard normal is bounded within $[0,1]$ as $R_{-n}$ diverges. Second, I claim that the equilibrium thresholds converge to $R_{1}^{* * *}=R_{2}^{* * *}=R^{* * *} \equiv 1+\chi\left[1-y_{1}-y_{2}\right]$ as the fundamental uncertainty vanishes. This is proven by contradiction.

I start by supposing that $R_{1}^{* * *}>R_{2}^{* * *}$. Then $W_{1,2}^{* * *} \rightarrow 0$ and $W_{2,1}^{* * *} \rightarrow 1$ as $\gamma \rightarrow \infty$. Insert these results into equation (23), the implied expressions for the thresholds can never satisfy the supposed inequality $R_{1}^{* * *}>R_{2}^{* * *}$. By extension, the argument applies for $R_{1}^{* * *}<R_{2}^{* * *}$ as well. Therefore, $R_{1}^{* * *}=R_{2}^{* * *}$ as claimed. Hence, the expression for $R^{* * *}$ obtains.

Third, liquidity must again be scarce to support positive liquidation as forecast by the thresh-

\footnotetext{
${ }^{20}$ In that paper, the uniqueness proof is in two steps. Using my notation here, a unique solution $R_{n}^{* * *}$ must be obtained for any $R_{-n}$ first, so $R_{n}^{* * *}\left(R_{-n}\right)$ is a best-response function for all $n$. Second, there must be a unique intersection of best response functions.
} 
old investor, $y_{n}<\frac{1}{2}$ for $n=1,2$. Furthermore, the equilibrium threshold confirms the supposition of $W_{n,-n}^{* * *} \leq y_{-n}$ if the other bank's liquidity holding is also scarce, $y_{-n}<\frac{1+\lambda}{2}$.

Digression: another liquidation cost specification The equilibrium threshold places an equal weight on the liquidity levels of either intermediary, as implied by the equal weight of the liquidation volumes in the liquidation cost function. This feature can be relaxed by either a larger weight on the own liquidation volume or by specifying a convex liquidation cost function. Both specification imply a larger weight of an intermediary's equilibrium threshold on its level of liquidity. For example, take a liquidation cost function that is proportional to both its individual liquidation volume and the aggregate liquidation volume: $\chi\left(l_{n}, l_{-n}\right)=\chi l_{n}\left(l_{n}+l_{-n}\right)$. This yields $R_{n}^{* * *} \rightarrow 1+\chi\left(1-y_{A}-y_{B}\right)\left(\frac{1}{2}-\right.$ $\left.y_{n}\right)$.

\section{A.6 Best-response function of private liquidity choice}

This section derives conditions sufficient for $y_{n}^{* * *}\left(y_{-n}\right)$ to be unique, thereby constituting a bestresponse function. This proof mirrors and extends the single-intermediary case in Appendix A.4.

Recall that $\Lambda\left(R_{n}^{* * *}\right)=\frac{1-\Phi\left(\sqrt{\alpha}\left[R_{n}^{* * *}-\bar{r}\right]\right)}{\phi\left(\sqrt{\alpha}\left[R_{n}^{* * *}-\bar{r}\right]\right)}>0$, where $R_{n}^{* * *}=1+\chi\left(1-y_{n}^{* * *}-y_{-n}\right)$. Thus, $\Lambda^{\prime}\left(R_{n}^{* * *}\right)=-\sqrt{\alpha}-\alpha\left(\bar{r}-R_{n}^{* * *}\right) \Lambda\left(R_{n}^{* * *}\right)<0$. Using $\Lambda\left(R_{n}^{* * *}\right)$, the first-order condition that determines the best-response function $y_{n}^{* * *}\left(y_{-n}\right)$ becomes:

$$
\chi^{2}\left(1-y_{n}^{* * *}\right)\left(1-y_{n}^{* * *}-y_{-n}\right)=\frac{1}{\alpha}+(\bar{r}-1) \Lambda\left(R_{n}^{* * *}\right)
$$

for any $y_{-n} \in[0,1]$.

Four checks are required to establish a best-response function. First, the left-hand side (LHS) of equation (61) is decreasing in the liquidity level $y_{n}$ over the relevant range $y_{n} \in\left[0, \frac{1}{2}\right)$ for all $y_{-n}$, while the right-hand side (RHS) is increasing in it:

$$
\begin{aligned}
& \frac{\partial L H S}{\partial y_{n}}=\chi^{2}\left[2 y_{n}+y_{-n}-2-\right]<-\chi^{2}\left(1-y_{-n}\right) \leq 0 \\
& \frac{\partial R H S}{\partial y_{n}}=-\chi(\bar{r}-1) \Lambda^{\prime}\left(R_{n}^{* * *}\right)>0
\end{aligned}
$$


Second, the left-hand side exceeds the right-hand side when evaluated at the lower bound $y_{n}=0$ for any liquidity level $y_{-n}$. This inequality is hardest to satisfy for $y_{-n} \rightarrow \frac{1}{2}$. Therefore, $\operatorname{LHS}\left(0, \frac{1}{2}\right) \geq R H S\left(0, \frac{1}{2}\right)$ is sufficient and yields an upper bound on the expected investment return $\bar{r}_{H}$; this bound is identical to the one that ensures an interior solution $y^{* *}$ in the one-bank case, $\bar{r} \leq \bar{r}_{H}$.

Third, the right-hand side exceeds the left-hand side when evaluated at the upper bound $y_{n} \rightarrow \frac{1}{2}$ for any liquidity level $y_{-n}$. This inequality is hardest to satisfy for $y_{-n}=0$. Therefore, $\operatorname{LHS}\left(\frac{1}{2}, 0\right) \leq R H S\left(\frac{1}{2}, 0\right)$ is sufficient and yields a lower bound on the expected investment return $\bar{r}_{2}$ implicitly defined by:

$$
\frac{\chi^{2}}{4} \equiv \frac{1}{\alpha}+\frac{\left(\bar{r}_{2}-1\right) \Phi\left(\sqrt{\alpha}\left[\bar{r}_{2}-1-\chi \frac{1}{4}\right]\right)}{\sqrt{\alpha} \phi\left(\sqrt{\alpha}\left[\bar{r}_{2}-1-\chi \frac{1}{2}\right]\right)}
$$

Define the lower bound on the expected return as $\bar{r}_{L} \equiv \max \left\{\bar{r}_{1}, \bar{r}_{2}\right\}$. Therefore, a solution $y_{n}^{* * *}\left(y_{-n}\right)$ to the first-order condition in equation (22) exists if $\bar{r} \in\left[\bar{r}_{L}, \bar{r}_{H}\right]$.

Fourth, the global concavity of the objective function in $y_{n}$ when evaluated at $R_{n}^{* * *}$ ensures that there this solution is unique:

$$
\frac{d^{2} E U_{n}}{d y_{n}^{2}}=\frac{\partial R_{n}^{* * *}}{\partial y_{n}}\left[2 \frac{\partial^{2} E U_{n}}{\partial y_{n} \partial R_{n}^{* * *}}+\frac{\partial^{2} E U_{n}}{\partial\left(R_{n}^{* * *}\right)^{2}} \frac{\partial R_{n}^{* * *}}{\partial y_{n}}\right]+\frac{\partial E U_{n}}{\partial R_{n}^{* * *}} \frac{\partial^{2} R_{n}^{* * *}}{\partial y_{n}^{2}}<0
$$

where $\frac{\partial^{2} R_{n}^{* * *}}{\partial y_{n}^{2}}=0$ and the sign follows directly from the previously established signs on the partial derivatives of the expected utility $E U_{n}$ for the equilibrium threshold $R_{n}^{* * *} \in(1, \bar{r})$, where the upper bound is implied by $\bar{r}>\bar{r}_{1}$.

In sum, $\bar{r}_{L} \leq \bar{r} \leq \bar{r}_{H}$ ensures that a best-response function $y_{n}^{* * *}\left(y_{-n}\right)$ exists.

\section{A.7 $\quad$ Strategic substitutability in liquidity holdings}

Strategic substitutability of bank liquidity holdings are established by totally differentiating equation (22):

$$
\frac{d y_{n}^{*}}{d y_{-n}}=-\frac{\chi^{2}\left[1-y_{n}^{* * *}\right]+\chi(\bar{r}-1)\left[-\Lambda\left(R_{n}^{* * *}\right)\right]}{\chi^{2}\left[2-2 y_{n}^{* * *}-y_{-n}\right]+\chi(\bar{r}-1)\left[-\Lambda\left(R_{n}^{* * *}\right)\right]} \in(-1,0)
$$

where the lower bound is ensured by $y_{k}<\frac{1}{2}, k=1,2$. 


\section{A.8 Constrained planner's problem}

Unique constraint efficient liquidity level This section shows that there exists a unique constrained efficient liquidity level. First, we require that the left-hand side of equation (34) exceeds the right-hand side at the lower bound $y_{\text {total }}^{S P}=0$, which implicitly defines an upper bound on the expected investment return $\bar{r}<\bar{r}_{H}^{S P}$ :

$$
2 \chi^{2} \equiv \frac{1}{\alpha}+\frac{\bar{r}_{H}^{S P}-1}{\sqrt{\alpha}} \Lambda\left(\sqrt{\alpha}\left[\bar{r}_{H}^{S P}-(1+\chi)\right]\right)
$$

Second, the right-hand side of equation (34) exceeds the left-hand side at the upper bound $y_{\text {total }} \rightarrow 1$, which is never binding. Third, the left-hand side of equation (34) strictly decreases in the liquidity level over the required range $[0,1)$, while the right-hand side of equation (34) strictly increases in it. Finally, verify that it is indeed a local maximum of the social welfare function:

$$
\frac{d^{2} S W F\left(y=y_{\text {total }}^{S P}\right)}{d\left(y^{S P}\right)^{2}}=-\sqrt{\alpha} \chi f\left(R^{S P}\right)\left(\sqrt{\alpha}(\bar{r}-1) \Lambda\left(R^{S P}\right)+\chi\left(3-y_{\text {total }}^{S P}\right)+(\bar{r}-1)\right)<0
$$

Taking these points together, there exists a unique level of total liquidity $y_{\text {total }}^{S P}$ that maximizes social welfare and is implicitly given by $\frac{d S W F}{d y_{n}}\left(y_{\text {total }}^{S P}\right)=0$.

Rankings of liquidity levels and equilibrium thresholds Solve for $y^{* * *}$ and $y^{S P}$ and substitute in defining equations, we get:

$$
\begin{aligned}
\left(R^{* * *}-1\right)\left(\frac{R^{* * *}-1+\chi}{2}\right) & =\frac{1}{\alpha}+\frac{\bar{r}-1}{\sqrt{\alpha}} \Lambda\left(R^{* * *}\right) \\
\left(R^{S P}-1\right)\left(R^{S P}-1+\chi\right) & =\frac{1}{\alpha}+\frac{\bar{r}-1}{\sqrt{\alpha}} \Lambda\left(R^{S P}\right)
\end{aligned}
$$

The right-hand side is identical, while the left-hand side is larger for the social planner allocation than for the private allocation, yielding $R^{S P}<R^{* *}<R^{* * *}$. Therefore, the privately optimal liquidity level are in sum smaller than the social planner's allocation, $y_{\text {total }}^{S P}<2 y^{* * *}$. 